Dirceu Thiago Pessoa de Melo

\title{
Impacto da pericardiectomia sobre a fisiologia cardiorrespiratória de pacientes com pericardite constritiva crônica durante a vigília e sono
}

\author{
Tese apresentada à Faculdade de \\ Medicina da Universidade de São Paulo \\ para obtenção do título de Doutor em Ciências
}

Programa de Cardiologia

Orientador: Prof. Dr. Fábio Fernandes

São Paulo

2017 
Dados Internacionais de Catalogação na Publicação (CIP)

Preparada pela Biblioteca da

Faculdade de Medicina da Universidade de São Paulo

Creprodução autorizada pelo autor

Melo, Dirceu Thiago Pessoa de

Impacto da pericardiectomia sobre a fisiologia cardiorrespiratória de pacientes com pericardite constritiva crônica durante a vigília e sono / Dirceu Thiago Pessoa de Melo. -- São Paulo, 2017.

Tese(doutorado)--Faculdade de Medicina da Universidade de São Paulo. Programa de Cardiologia.

Orientador: Fábio Fernandes.

Descritores: 1.Pericardite constritiva 2.Pericardiectomia 3.Insuficiência cardíaca 4.Tolerância ao exercício 5.Peptídeo natriurético tipo B 6.Apneia do sono 7.Polissonografia

USP/FM/DBD-012/17 
Dedicatória 
Ao meu pai (in memoriam), Paulo, por me ensinar a sonhar e acreditar sempre. À minha mãe, Janeide, pelo exemplo de generosidade e apoio desde o início desta longa jornada.

Aos meus irmãos Luiza, Fernando e Gabriela, parceiros pra vida toda. Ao meu amor, Júlia, companheira de todas as horas. Aos meus filhos Paulo e Matheus, fonte maior de minha alegria. 
Agradecimentos 
Ao meu orientador e amigo, Prof. Dr. Fábio Fernandes, pelo apoio em todas as fases da tese e por me ensinar os primeiros passos na ciência. Sem dúvida, um exemplo de médico, pesquisador e sobretudo ser humano.

Ao Prof. Dr. Geraldo Lorenzi-Filho pelas valiosas contribuições na concepção e análise do estudo.

A toda equipe da Unidade de Miocardiopatias e Doenças da Aorta do InCor. Vocês proporcionaram um excelente ambiente de trabalho e constante estimulo à pesquisa.

À secretária da Unidade de Miocardiopatias do InCor, Roseli Chaves, pela ajuda essencial para realização dos exames da tese.

À enfermeira Paula Buck, pelo apoio constante no recrutamento de pacientes.

À Lucia Oliveira, fundamental para obtenção do auxílio financeiro do projeto.

À Flávia Nerbass, do Laboratório do Sono do InCor, pela imensa ajuda com os laudos das polissonografias e discussões sobre medicina do sono.

À Viviane Hotta, pela realização dos laudos do ecocardiograma. Seu esforço foi fundamental na finalização da tese.

À Vera Salemi, pela realização dos ecocardiogramas.

À Ana Sayegh e Francis Ribeiro, fundamentais para realização e interpretação do teste cardiopulmonar.

A todos os amigos do Hospital do Coração de Campinas, especialmente Fábio Rossi, pela força nos momentos mais difíceis. Principalmente na árdua tarefa de conciliar trabalho e vida acadêmica.

À minha amiga e parceira de trabalho Rita Rodrigues, que tanto me ajudou nos momentos em que precisei estar ausente. 
Aos membros da minha banca de qualificação, Dr. Luciano Drager, Dra. Silvia Ayub e Dr. Heno Lopes pelas valiosas contribuições para a finalização da tese.

À Comissão de Pós-Graduação, especialmente a Juliana Lattari e Neusa Dino, pelo suporte que proporcionaram em todas as etapas do programa.

À Fundação de Amparo à Pesquisa do Estado de São Paulo (FAPESP), pelo suporte financeiro ao projeto.

Aos pacientes, que generosamente dedicaram tempo à realização desta pesquisa e tornaram tudo possível. 
Epígrafe 
“A vida é assim: esquenta e esfria, aperta e daí afrouxa.... o que ela quer da gente é coragem." - João Guimarães Rosa 


\section{Normalização}

Esta tese está de acordo com as seguintes normas, em vigor no momento desta publicação:

Referências: adaptado de International Committee of Medical Journals Editors (Vancouver). Universidade de São Paulo. Faculdade de Medicina. Divisão de Biblioteca e Documentação. Guia de apresentação de dissertações, teses e monografias. Elaborado por Anneliese Carneiro da Cunha, Maria Julia de A. L. Freddi, Maria F. Crestana, Marinalva de Souza Aragão, Suely Campos Cardoso, Valéria Vilhena. 3a ed. São Paulo: Divisão de Biblioteca e Documentação; 2011. Abreviaturas dos títulos dos periódicos de acordo com List of Journals Indexed in Index Medicus. 


\section{SUMÁRIO}

\section{Lista de abreviaturas}

Lista de símbolos

Lista de tabelas

Lista de figuras

\section{RESUMO}

\section{ABSTRACT}

1 INTRODUÇÃO.

01

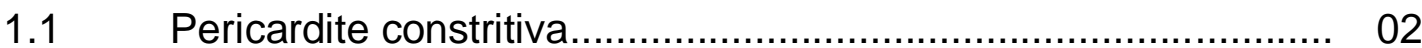

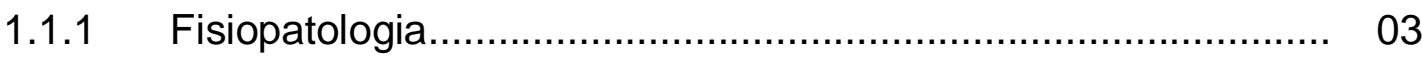

1.1.2 Quadro clínico e diagnóstico.................................................... 06

1.2 Apneia do sono e pericardite constritiva.................................. 07

1.2.1 Apneia obstrutiva do sono.................................................. 09

1.2.2 Apneia central do sono e Respiração de Cheyne-Stokes........... 10

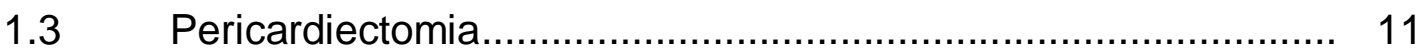

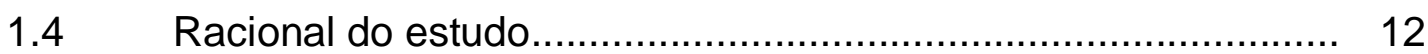

2 OBJETIVOS.......................................................................... 13

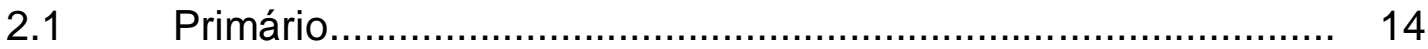

2.2 Secundários............................................................... 14

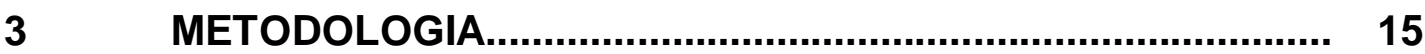

3.1 Seleção de pacientes............................................................ 16

3.2 Desenho do estudo........................................................ 16

3.3 Métodos complementares.................................................. 17

3.3.1 Ecocardiograma transtorácico ............................................. 17 
3.3.2 Polissonografia noturna completa.......................................... 19

3.3.3 Teste de esforço cardiopulmonar............................................ 20

3.3.4 Peptídeo natriurético tipo B................................................. 21

3.3.5 Questionários.................................................................. 21

3.3.5.1 Escala de Sonolência de Epworth............................................ 21

3.3.5.2 Índice de Qualidade do Sono de Pittsburgh.............................. 22

3.3.5.3 Questionário Minnesota......................................................... 22

3.4 Análise estatística e tamanho amostral................................... 22

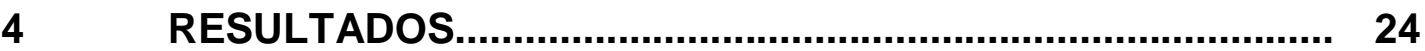

4.1 Dados gerais............................................................ 25

4.2 Efeito da pericardiectomia sobre características clínicas e qualidade de vida............................................................. 27

4.3 Ecocardiograma................................................................ 30

4.4 Teste de esforço cardiopulmonar............................................ 32

4.5 Polissonografia noturna completa e questionários do sono........ 33

4.6 Comparação dos pacientes com e sem apneia moderada/grave

4.5 Avaliação de preditores de melhora da capacidade de exercício após a pericardiectomia............................................ 37

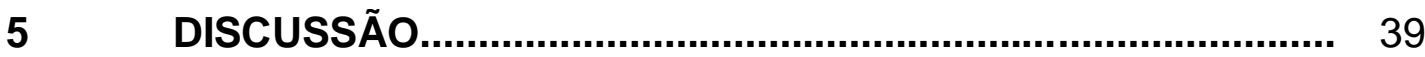

5.1 Características da amostra.................................................... 40

5.2 Teste de esforço cardiopulmonar.......................................... 41

5.3 Estudo do sono................................................................... 42

5.4 Ecocardiograma................................................................ 44 


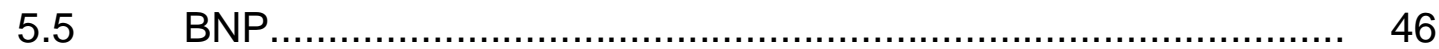

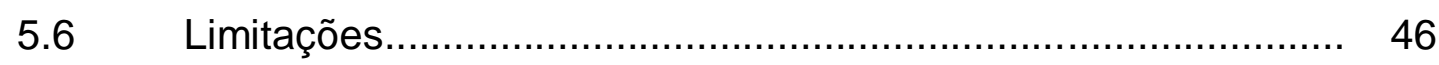

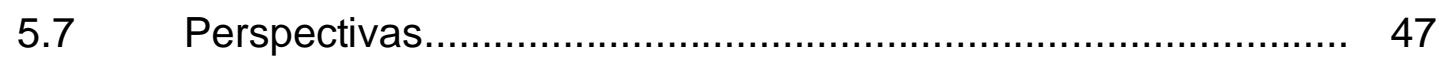

$6 \quad$ CONCLUSÕES........................................................... 49

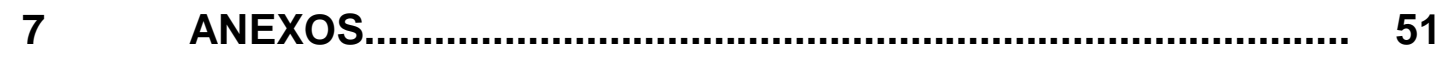

$8 \quad$ REFERÊNCIAS.............................................................. 67 
Listas 


\section{Lista de Abreviaturas}

AE

AOS

BNP

BRA

$\mathrm{CO} 2$

DDVE

DSVE

Ei

Ee

Exp

ECG

EuroSCORE

FAPESP

FC

FEVE

HCFMUSP

$\mathrm{IAH}$

IC

IECA

IMC

InCor

Insp

LA

LA-VO2
Átrio esquerdo

Apneia obstrutiva do sono

Peptídeo natriurético tipo $B$

Bloqueador do receptor de angiotensina

Gás carbônico

Diâmetro diastólico do ventrículo esquerdo

Diâmetro sistólico do ventrículo esquerdo

Onda E inspiratória

Onda E expiratória

Expiração

Eletrocardiograma

European System for Cardiac Operative Risk Evaluation

Fundação de Amparo à Pesquisa do Estado de São Paulo

Frequência cardíaca

Fração de ejeção do ventrículo esquerdo

Hospital das Clínicas da Faculdade de Medicina da Universidade de São Paulo

Índice de apneia-hipopneia

Insuficiência cardíaca

Inibidor da enzima conversora de angiotensina

Índice de massa corpórea

Instituto do Coração

nspiração

Limiar anaeróbico

Consumo de oxigênio no limiar anaeróbico 
NREM

NT-pro-BNP

NYHA

$\mathrm{PaCO} 2$

PAD

PAS

PCC

PCR

PCR-VO2

PetCO2

PSAP

PSG

REM

RER

$\mathrm{SpO} 2$

TCLE

TD

TGF- $\beta 1$

UTI

VCO2

VD

VE

$\mathrm{V}_{\mathrm{E}}$

VHS

VO2
Non rapid eye movement

Fração N-terminal do pró-hormônio BNP

New York Heart Association

Pressão parcial de CO2

Pressão arterial diastólica

Pressão arterial sistólica

Pericardite constritiva crônica

Ponto de compensação respiratória

Consumo de oxigênio no ponto de compensação respiratória

Pressão parcial de dióxido de carbono

Pressão sistólica da artéria pulmonar

Polissonografia

Rapid eye movement

Razão de troca respiratória

Saturação periférica de oxigênio

Termo de consentimento livre e esclarecido

Tempo de desaceleração

Transforming growth factor beta 1

Unidade de terapia intensiva

Produção de dióxido de carbono

Ventrículo direito

Ventrículo esquerdo

Ventilação pulmonar

Velocidade de hemossedimentação

Consumo de oxigênio 


\section{Lista de símbolos}

\begin{tabular}{|c|c|}
\hline bpm & batimento por minuto \\
\hline $\mathrm{cm}$ & centímetro \\
\hline $\mathrm{cm} / \mathrm{s}$ & centímetro por segundo \\
\hline$E$ & onda diastólica precoce \\
\hline$E / e^{\prime}$ & relação entre as ondas E e e' \\
\hline$e^{\prime}$ & velocidade diastólica precoce \\
\hline eventos/h & eventos por hora \\
\hline$g$ & grama \\
\hline$g / d L$ & grama por decilitro \\
\hline $\mathrm{kg}$ & quilograma \\
\hline $\mathrm{kg} / \mathrm{m}^{2}$ & quilograma por metro quadrado \\
\hline $\mathrm{L}$ & litro \\
\hline $\mathrm{m}$ & metro \\
\hline$m^{2}$ & metro quadrado \\
\hline $\mathrm{mg}$ & miligrama \\
\hline $\min$ & minuto \\
\hline $\mathrm{mg} / \mathrm{dL}$ & miligrama por decilitro \\
\hline $\mathrm{mL}$ & mililitro \\
\hline $\mathrm{mL} / \mathrm{kg} / \mathrm{min}$ & mililitro por quilograma por minuto \\
\hline $\mathrm{mm}$ & milímetro \\
\hline $\mathrm{mmHg}$ & milímetros de mercúrio \\
\hline $\mathrm{mph}$ & milhas por hora \\
\hline $\mathrm{ms}$ & milissegundo \\
\hline $\mathrm{pg} / \mathrm{mL}$ & picograma por mililitro \\
\hline
\end{tabular}


$\pm$

$<$

$\leq$

$>$

$\geq$

$\%$

$\Delta$

mais ou menos

menor

menor ou igual

maior

maior ou igual

porcentagem

diferença 


\section{Lista de tabelas}

Tabela 1. Classificação das principais síndromes pericárdicas.............. 03

Tabela 2. Principais achados do ecocardiograma transtorácico na pericardite constritiva.................................................... 07

Tabela 3. Características clínicas e laboratoriais pré-operatórias........... 26

Tabela 4. Efeito da pericardiectomia nos parâmetros antropométricos, clínicos e laboratoriais.................................................. 28

Tabela 5. Comparação das medicações utilizadas no pré e pósoperatório 29

Tabela 6. Efeito da pericardiectomia sobre a qualidade de vida............. 30

Tabela 7. Comparação do ecocardiograma no pré e pós-operatório....... 31

Tabela 8. Comparação do teste de esforço cardiopulmonar no pré e pós-operatório............................................................. 32

Tabela 9. Comparação do estudo do sono no pré e pós-operatório........ 34

Tabela 10. Comparação dos dados clínicos de pacientes com e sem apneia moderada/ grave

Tabela 11. Comparação do teste cardiopulmonar de esforço de pacientes com e sem apneia moderada/grave.

Tabela 12. Análise univariada dos preditores de variação do VO2 pico predito 


\section{Lista de figuras}

Figura 1. Interdependência ventricular e dissociação entre as pressões intratorácicas e intracardíacas na pericardite constritiva......... 05

Figura 2. Polissonografia de um paciente com apneia obstrutiva do sono.

Figura 3. Polissonografia de um paciente com apneia central e respiração de Cheyne-Stokes.

Figura 4. Fluxograma do estudo.

Figura 5. Melhora da classe funcional New York Heart Association após pericardiectomia

Figura 6. Correlação entre VO2 pico predito e qualidade de vida no pré-operatório.

Figura 7. Correlação entre o índice de apneia-hipopneia e níveis séricos de BNP no pré-operatório. 35

Figura 8. Correlação entre a variação do VO2 pico predito e idade..... 38 
Resumo 
Melo DTP. Impacto da pericardiectomia sobre a fisiologia cardiorrespiratória de pacientes com pericardite constritiva crônica durante a vigília e sono [Tese]. São Paulo: Faculdade de Medicina, Universidade de São Paulo; 2017.

Introdução: A pericardiectomia é o tratamento de escolha para pacientes com pericardite constritiva crônica sintomática, entretanto, o impacto do procedimento na capacidade cardiopulmonar e fisiologia cardiorrespiratória durante a vigília e sono é pouco estudado. Objetivo: Avaliar o impacto da cirurgia de pericardiectomia sobre a capacidade funcional de pacientes com pericardite constritiva crônica sintomática. Métodos: Trata-se de estudo observacional prospectivo com 25 pacientes consecutivos com diagnóstico de pericardite constritiva crônica submetidos à pericardiectomia. Foram realizados os seguintes procedimentos uma semana antes e seis meses após a pericardiectomia: avaliação clínica e antropométrica, avaliação da qualidade de vida e do sono, dosagem dos níveis séricos de BNP, ecocardiograma transtorácico, teste cardiopulmonar de esforço, polissonografia noturna completa. Resultados: A idade média foi 45 anos, com predomínio do sexo masculino (76\%). A etiologia foi principalmente idiopática (76\%), seguida por tuberculose (12\%). O ecocardiograma revelou fração de ejeção do ventrículo esquerdo preservada e dilatação de veia cava inferior (92\%) na maioria dos pacientes. Todos os pacientes foram submetidos à pericardiectomia de frênico a frênico via esternotomia mediana, sem circulação extracorpórea. Após a pericardiectomia, houve redução da: classe funcional III/IV (56\% vs. $8 \%$, $p<0,001)$, ascite $(72 \%$ vs. $12 \%, p<0,001)$ e edema de membros inferiores $(88 \%$ vs. $24 \%, p<0,001)$ em relação ao pré-operatório. O teste cardiopulmonar revelou melhora do VO2 pico $(18,7 \pm 5,6$ vs. $25,2 \pm 6,3 \mathrm{~mL} / \mathrm{kg} / \mathrm{min}, p<0,001)$, limiar anaeróbico $(13,1 \pm 3$ vs. $17,7 \pm 5,5 \mathrm{~mL} / \mathrm{kg} / \mathrm{min}, p<0,001)$ e velocidade na esteira rolante de $2,5(2-2,5)$ para $3(2,5-3,3) \mathrm{mph}, \mathrm{p}=0,001$. Na análise multivariada, a idade foi o único preditor independente da variação de VO2 ( $r=-$ $0,658, p=0,003)$. Os níveis séricos de BNP apresentaram redução significativa de $143(83,5-209,5) \quad \mathrm{pg} / \mathrm{mL}$ para $76(40-117,5) \quad \mathrm{pg} / \mathrm{mL}, \quad \mathrm{p}=0,011$. A 
polissonografia noturna completa no pré-operatório demonstrou a presença de apneia do sono moderada/ grave (IAH $\geq 15$ eventos/hora) em 13 pacientes, com predomínio de hipopneias. Não houve mudança significativa do índice de apneia-hipopneia após a pericardiectomia: IAH pré $15,6(8,3-31,7)$ vs. IAH pós 14,6 (5,75-29,9), $p=0,253$; entretanto, houve melhora da qualidade do sono (Pittsburgh pré $7,8 \pm 4,10$ vs. Pittsburgh pós $4,7 \pm 3,7, p<0,001)$. O IAH apresentou correlação positiva com os níveis de BNP $(r=0,418, p=0,037)$ e EuroSCORE $(r=0,480, p=0,015)$ no pré-operatório. Conclusão: Pacientes com pericardite constritiva crônica sintomática apresentaram, seis meses após a cirurgia de pericardiectomia, melhora da capacidade cardiopulmonar, da classe funcional e da qualidade de vida. A apneia do sono se mostrou frequente e apresentou correlação com níveis séricos de BNP e EuroSCORE no préoperatório. O índice de apneia-hipopneia não apresentou mudanças significativas após a pericardiectomia. A despeito disso, houve melhora da qualidade do sono.

Descritores: pericardite constritiva; pericardiectomia; insuficiência cardíaca; tolerância ao exercício; peptídeo natriurético tipo B; apneia do sono; polissonografia. 
Abstract 
Melo DTP. Impact of pericardiectomy on cardiorespiratory physiology of patients with chronic constrictive pericarditis during wakefulness and sleep [Thesis]. São Paulo: "Faculdade de Medicina, Universidade de São Paulo"; 2017.

Introduction: Pericardiectomy is the treatment of choice for patients with symptomatic chronic constrictive pericarditis; however, the impact of the procedure on cardiopulmonary capacity and cardiorespiratory physiology during wakefulness and sleep has been poorly studied so far. Objective: To evaluate the impact of pericardiectomy surgery on functional capacity of patients with symptomatic chronic constrictive pericarditis. Methods: This is a prospective observational study with 25 consecutive patients diagnosed with chronic constrictive pericarditis submitted to pericardiectomy. The following procedures were performed one week before and six months after pericardiectomy: clinical and anthropometric evaluation, quality of life and sleep evaluation, serum BNP levels, transthoracic echocardiography, cardiopulmonary exercise test, complete nocturnal polysomnography. Results: The mean age was 45 , with a predominance of males $(76 \%)$. The etiology was mainly idiopathic $(76 \%)$, followed by tuberculosis (12\%). The echocardiogram revealed preserved left ventricular ejection fraction and inferior vena cava dilatation (92\%) in most patients. All patients underwent phrenic to phrenic pericardiectomy via median sternotomy, without extracorporeal circulation. After pericardiectomy there was a reduction in: functional class III / IV ( $56 \%$ vs. $8 \%, p<0.001)$, ascites $(72 \%$ vs. $12 \%, p<0.001)$ and lower limb edema ( $88 \%$ vs. $24 \%, p<0.001)$ as compared to the preoperative period. The cardiopulmonary test revealed improvement in VO2 peak ( $18.7 \pm 5.6$ vs. $25.2 \pm 6.3 \mathrm{~mL} / \mathrm{kg} / \mathrm{min}, \mathrm{p}<0.001$ ), anaerobic threshold (13.1 \pm 3 vs. $17.7 \pm 5.5 \mathrm{~mL} / \mathrm{kg} / \mathrm{min}, \mathrm{p}<0.001)$ and velocity on the treadmill from $2.5(2-2.5)$ to $3(2.5-3.3) \mathrm{mph}, \mathrm{p}=0.001$. In multivariate analysis, age was the only independent predictor of VO2 variation $(r=-0.658, p=0.003)$. Serum BNP levels showed a significant reduction from $143(83.5-209.5) \mathrm{pg} / \mathrm{mL}$ to 76 (40117.5) $\mathrm{pg} / \mathrm{mL}, \mathrm{p}=0.011$. The complete nocturnal polysomnography in the 
preoperative period showed moderate / severe sleep apnea (AHI $\geq 15$ events / hour) in 13 patients, predominantly hypopnea. There was no significant change in apnea-hypopnea index after pericardiectomy: AHI pre 15.6 (8.3-31.7) vs. AHI post 14.6 (5.75-29.9), $p=0.253$; however, there was improvement in sleep quality (Pittsburgh pre $7.8 \pm 4.10$ vs. Pittsburgh post $4.7 \pm 3.7, p<0.001$ ). AHI presented a positive correlation with BNP levels $(r=0.418, p=0.037)$ and EuroSCORE $(r=0.480 ; p=0.015)$ in the preoperative period. Conclusion: Patients with symptomatic chronic constrictive pericarditis showed improvement in cardiopulmonary capacity, functional class and quality of life six months after pericardiectomy. Sleep apnea was frequent and correlated with serum levels of BNP and EuroSCORE in the preoperative period. The apnea-hypopnea index did not show significant changes after pericardiectomy. Nevertheless, there was an improvement in sleep quality.

Descriptors: pericarditis, constrictive; pericardiectomy; heart failure; exercise tolerance; natriuretic peptide B; sleep apnea; polysomnography. 
Introdução 


\section{INTRODUÇÃO}

\subsection{Pericardite constritiva}

A pericardite constritiva é uma doença caracterizada pela inflamação, fibrose e perda de elasticidade do pericárdio, levando a restrição do enchimento ventricular e disfunção diastólica. ${ }^{1}$ Trata-se de sequela de uma agressão pericárdica, porém os mecanismos fisiopatológicos que determinam seu surgimento ainda são pouco conhecidos. O risco de desenvolver pericardite constritiva após pericardite aguda depende essencialmente da etiologia: $0,2 \%$ após cirurgia cardíaca, $0,5-1 \%$ após pericardites virais/ idiopáticas e 20-30\% após pericardites bacteriana e tuberculosa. ${ }^{2-4} \mathrm{Em}$ geral, acomete mais comumente o sexo masculino. ${ }^{5}$ Em países desenvolvidos, as principais causas são: viral/idiopática, pós-cirurgia cardíaca e pós-radioterapia. ${ }^{6}$ No Brasil, dados da literatura são escassos. Em séries de casos nacionais a maioria é idiopática (51-70\%), seguida pela tuberculose $(20 \%){ }^{7,8}$

A pericardite constritiva pode se manifestar de diferentes formas de acordo com tempo de evolução (aguda, subaguda, crônica), grau de espessamento pericárdico (localizado, difuso, calcificado) ou a presença de derrame pericárdico. ${ }^{9}$ A tabela 1 resume a classificação das síndromes constritivas proposta pela diretriz europeia de doenças do pericárdio. ${ }^{4}$ 
Tabela 1 - Classificação das principais síndromes pericárdicas

\begin{tabular}{ll}
\hline Síndrome & Definição \\
\hline $\begin{array}{l}\text { Pericardite } \\
\text { constritiva transitória }\end{array}$ & $\begin{array}{l}\text { Espessamento e/ou perda da elasticidade do pericárdio em } \\
\text { decorrência de processo inflamatório agudo/ subagudo, com } \\
\text { resolução espontânea ou após tratamento medicamentoso } \\
\text { (em 3-6 meses). }\end{array}$ \\
$\begin{array}{l}\text { Pericardite } \\
\text { efusivo-constritiva }\end{array}$ & $\begin{array}{l}\text { Espessamento e/ou perda da elasticidade do pericárdio em } \\
\text { derrame pericárdico. Pode ser agudo ou não. }\end{array}$ \\
Pericardite & $\begin{array}{l}\text { Espessamento e/ou perda da elasticidade do pericárdio em } \\
\text { constritiva crônica }\end{array}$ \\
& fibrose e calcificação (30 \% dos casos). \\
\hline
\end{tabular}

Em virtude de sua fisiopatologia peculiar, a pericardite constritiva crônica (PCC) é frequentemente confundida com outras causas de insuficiência cardíaca, além de doenças hepáticas e pulmonares. Entretanto, o diagnóstico correto é fundamental, uma vez que a doença pode ser curada com a cirurgia de pericardiectomia. ${ }^{10}$

\subsubsection{Fisiopatologia}

O pericárdio é uma membrana formada por dois folhetos, visceral e parietal, compostos por fibras de colágeno, elásticas e células mesoteliais. Entre as camadas visceral e parietal existe uma cavidade que contém cerca de 15-50 mL de ultrafiltrado plasmático. O pericárdio tem como função a sustentação do coração, proteção e redução de atrito com as estruturas do mediastino. Além disso, exerce efeito mecânico sobre o coração ao impedir a dilatação excessiva das câmaras cardíacas em situações de sobrecarga aguda de volume (ex. infarto de ventrículo direito, regurgitação valvar aguda). ${ }^{11}$

Em pacientes com pericardite constritiva, o pericárdio rígido e inelástico determina o encarceramento do coração. Dessa forma, as câmaras cardíacas 
passam a funcionar dentro de uma cavidade com volume fixo e isolada das variações de pressão intratorácica. ${ }^{12}$ Esse fenômeno nos permite compreender as principais características fisiopatológicas da doença (Figuras 1A e 1B):

$\checkmark$ Pressões elevadas de enchimento ventricular: no momento em que se abrem as valvas atrioventriculares, ocorre rápido enchimento dos ventrículos e aumento abrupto da pressão diastólica. Como resultado, a maior parte do enchimento ventricular ocorre no terço inicial da diástole e, a partir do momento em que o pericárdio determina a máxima expansão da cavidade, cessa o aumento de volume e de pressão em seu interior. Estas alterações determinam no cateterismo direito o padrão chamado de "dip" (descenso Y rápido) e "plateau", ou "sinal da raiz quadrada". Na curva de pressão venosa observamos queda inicial da pressão, aumento abrupto e estabilização. Além disso, ocorre equalização das pressões de enchimento nas quatro câmaras cardíacas. $^{13,14}$

$\checkmark$ Interdependência ventricular: a inspiração determina aumento do retorno venoso para as câmaras direitas do coração e diminuição para as câmaras esquerdas. Em pacientes com fisiologia constritiva 0 ventrículo direito, ao receber maior volume sanguíneo durante a diástole, é impedido pelo pericárdio espessado de expandir sua parede livre. Como resultado, ocorre desvio do septo interventricular em direção ao ventrículo esquerdo, com consequente redução de seu enchimento diastólico, volume e pressão sistólicos. Assim, na inspiração ocorre aumento das pressões de enchimento em câmaras direitas associado à redução da pré-carga em câmaras esquerdas e do débito cardíaco. $O$ fenômeno oposto ocorre na expiração. ${ }^{14,15}$

$\checkmark$ Disfuncão miocárdica: a presença de pericárdio espessado e rígido aderido ao miocárdio pode causar distorções na geometria ventricular e alterações de contratilidade (mecanismo de tethering). ${ }^{16,17}$ Esses fenômenos podem agravar as disfunções sistólica e diastólica. 
Expiração
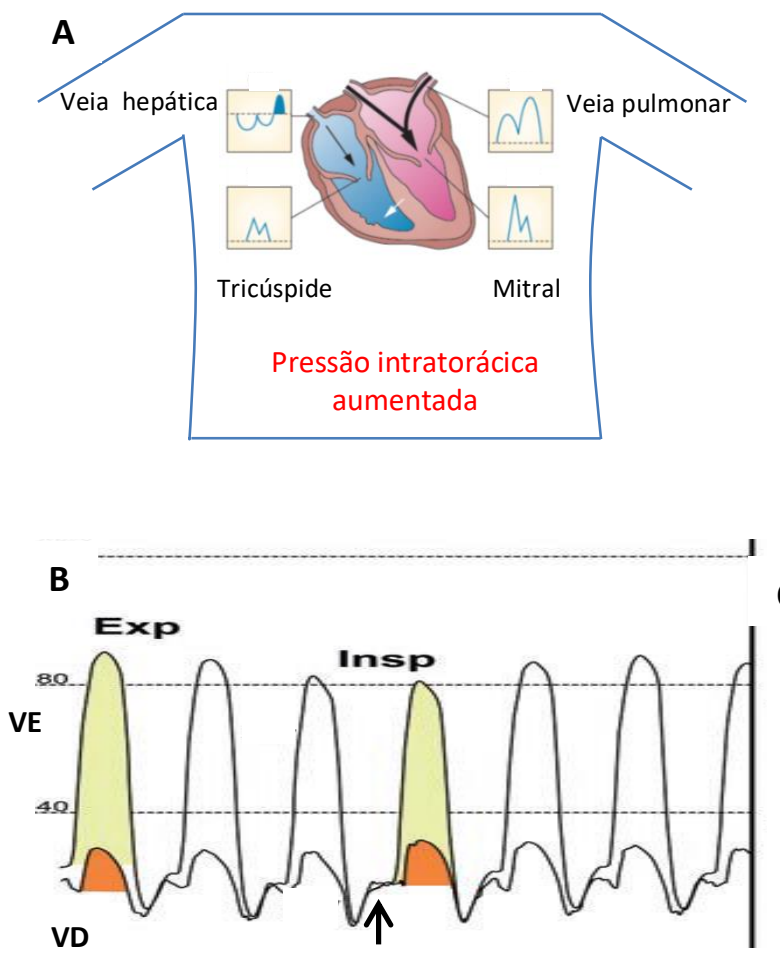

Inspiração

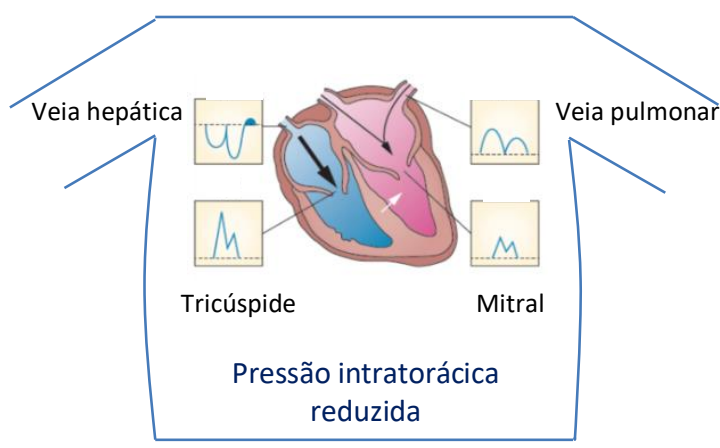

C

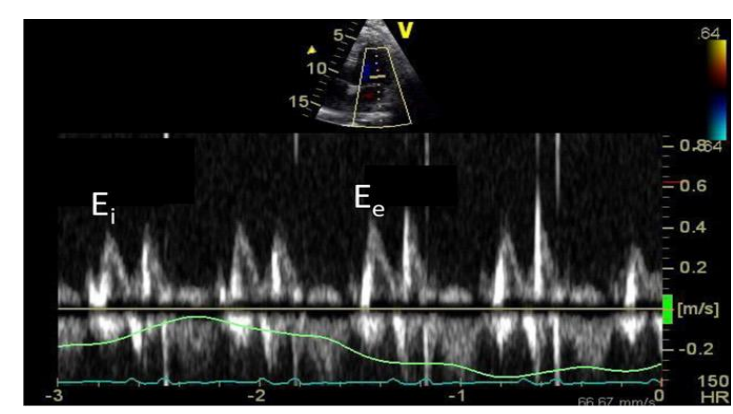

Figura 1 - Interdependência ventricular e dissociação entre as pressões intratorácicas e intracardíacas na pericardite constritiva. A: Observa-se a variação da movimentação do septo interventricular (seta branca) e dos fluxos valvares ao longo do ciclo respiratório. B: Curvas das medidas invasivas de pressão no VE e VD. Observa-se o sinal da raiz quadrada (seta preta). Em amarelo, o aumento da área sob a curva da pressão em VE na expiração e redução da inspiração. Em laranja, alterações opostas ocorrem no VD. Este padrão é chamado de interdependência ventricular, marco fisiopatológico da pericardite constritiva. C: Exemplo de ecocardiograma com respirômetro nasal. Observa-se o Doppler mitral revelando redução da onda E na inspiração. Exp: expiração; Insp: inspiração; VE: ventrículo esquerdo; VD: ventrículo direito; Ei: onda E na inspiração; Ee: onda E na expiração. Fonte: Klein et al. J Am Soc Echocardiogr. 2013;26(9):965-1012. ${ }^{1}$ 
$\mathrm{Na}$ presença das alterações acima descritas, há ativação do sistema renina-angiotensina, elevação dos níveis de catecolaminas e cortisol séricos, além de retenção de sódio e água. ${ }^{18}$ Os níveis séricos de peptídeo natriurético tipo B (BNP) em geral são normais ou pouco elevados, em virtude da menor distensão das fibras miocárdicas em presença de um pericárdio inelástico circunjacente. Entretanto, podem estar elevados nos casos mais graves e se associar a maior mortalidade pós-operatória. ${ }^{7}$ Níveis séricos baixos de BNP em presença de insuficiência cardíaca direita podem sugerir o diagnóstico de PCC e auxiliar no diagnóstico diferencial com miocardiopatias restritivas. ${ }^{19,20}$

\subsubsection{Quadro clínico e diagnóstico}

A pericardite constritiva deve ser considerada em pacientes com insuficiência cardíaca (IC) de predomínio à direita e função sistólica biventricular preservada. Turgência jugular, ascite e edema de membros inferiores são comuns, e podem ser agravados pela enteropatia perdedora de proteínas e cirrose cardíaca. Dois achados sugestivos ao exame físico são o sinal de Kussmaul (aumento de turgência jugular com a inspiração) e o knock pericárdico (som rude, protodiastólico, que ocorre devido à vibração da parede ventricular na fase de enchimento rápido). ${ }^{21} \mathrm{~A}$ presença de calcificação pericárdica na radiografia de tórax é sugestiva do diagnóstico, entretanto, está presente em apenas $25-30 \%$ dos casos. ${ }^{5}$

Os pacientes com PCC apresentam importante limitação da capacidade funcional. Nas principais séries de casos da literatura, a presença de classe funcional NYHA III/IV variou de 43 a $69 \% .{ }^{5,10}$ No entanto, não há dados sobre a qualidade de vida e avaliação objetiva da capacidade de exercício.

O diagnóstico é baseado na história e exame clínicos associados à documentação da interdependência ventricular e variação respiratória do fluxo valvar em exames de imagem. O espessamento pericárdico pode estar ausente em $18 \%$ dos casos. $^{22} \mathrm{O}$ ecocardiograma é o exame inicial de escolha, seus principais achados estão resumidos na Tabela $1 .^{11}$ 
Tabela 2 - Principais achados do ecocardiograma transtorácico na pericardite constritiva

\begin{tabular}{ll}
\hline Modo M & Variação respiratória do movimento septal \\
\hline Bidimensional & Espessamento do pericárdio $>4 \mathrm{~mm}$ \\
& Bounce septal, dilatação da veia cava inferior e das veias \\
& hepáticas com ausência de colapso inspiratório \\
& Redução $>25 \%$ da onda E mitral na inspiração \\
Doppler & Aumento $>40 \%$ da onda E tricúspide na inspiração \\
& Aumento do Fluxo diastólico reverso nas veias hepáticas \\
& e' mitral $>7 \mathrm{~cm} / \mathrm{s}$ \\
Doppler tecidual & e' mitral septal> e' lateral (Annulus reversus) \\
& Annulus paradoxus: relação inversa entre pressão de átrio \\
& esquerdo e E/e'
\end{tabular}

A ressonância magnética cardíaca é útil para a avaliação morfológica e funcional de pacientes com pericardite constritiva. ${ }^{23,24} \mathrm{O}$ exame permite a visualização direta do pericárdio, como também alterações no contorno ventricular, bounce septal e dilatação da veia cava inferior. Em estudo de Thavendiranathan et al, a ressonância apresentou acurácia de 93\% para diferenciação entre PCC e miocardiopatias restritivas. ${ }^{25}$ Além disso, a pesquisa de realce tardio com gadolínio pode evidenciar inflamação e fibrose do pericárdio, abrindo perspectivas para o tratamento etiológico medicamentoso. ${ }^{26-}$ ${ }^{27}$ Em estudo de Feng et al, a presença de inflamação pericárdica avaliada pelo realce tardio com gadolínio, proteína c-reativa e VHS apresentou sensibilidade de $86 \%$ e especificidade de $80 \%$ para predizer reversão da constrição com uso de anti-inflamatórios e corticoides em período médio de 13 meses. ${ }^{27}$

\subsection{Apneia do sono e pericardite constritiva}

A relação entre os distúrbios do sono e insuficiência cardíaca está bem estabelecida na literatura. No entanto, não existem estudos correlacionando apneia do sono e pericardite constritiva, tampouco sua relação com os efeitos hemodinâmicos da cirurgia de pericardiectomia.

Os principais distúrbios respiratórios do sono são a apneia do sono obstrutiva e central. A apneia do sono é caracterizada por pausas na 
respiração durante o sono. Pode ser classificada em obstrutiva, quando causada por obstrução faríngea ao fluxo de ar; central quando causada por alteração do drive ventilatório; ou mista quando ocorre a associação de mecanismos. ${ }^{28}$ Trata-se de doença prevalente e que pode ser considerada tanto causa como consequência de insuficiência cardíaca. ${ }^{29} \mathrm{O}$ exame de escolha para o diagnóstico da apneia do sono é a polissonografia, que fornece informações sobre a arquitetura e eficiência do sono e apresenta acurácia superior a $90 \% .^{30}$

Em indivíduos normais a apneia do sono obstrutiva aumenta em 2,38 vezes o risco de desenvolver insuficiência cardíaca. ${ }^{31}$ Nesses pacientes, o sono fragmentado, episódios de hipoxemia e variações da pressão arterial geram lesão endotelial e remodelamento cardíaco. ${ }^{32}$ Por outro lado, em indivíduos com insuficiência cardíaca a presença de baixo débito cardíaco, congestão pulmonar, edema de vias aéreas e ativação do sistema nervoso simpático parecem contribuir para o surgimento de distúrbios do sono, gerando um círculo vicioso. ${ }^{33-36}$ Como resultado, observa-se que mais da metade dos pacientes com insuficiência cardíaca tem apneia do sono, seja central ou obstrutiva. $^{37,38}$ Nessa população, a presença de apneia está relacionada a maior risco de arritmias atriais e ventriculares, pior qualidade de vida e aumento de mortalidade..$^{39-42}$

Estudos recentes têm revelado que a presença de apneia do sono em pacientes com IC parece estar relacionada à dinâmica de fluidos corporais. Em estudo de Yumino et al, o desvio noturno de líquidos dos membros inferiores para a região cervical e pulmões apresentou correlação direta com a presença de apneia do sono obstrutiva e central. ${ }^{34}$ Esses achados abrem perspectivas para novos estudos que investiguem os efeitos do tratamento da IC na apneia do sono. 


\subsubsection{Apneia obstrutiva do sono}

A apneia obstrutiva do sono (AOS) é definida como pausa respiratória (redução do volume corrente $\geq 90 \%$ ) de duração mínima de dez segundos e associada a esforço inspiratório. ${ }^{43}$ Predomina em homens, obesos e idosos, geralmente associada a roncos, sonolência diurna, sono não reparador e déficits de memória e atenção. ${ }^{29}$ Em pacientes com IC, no entanto, as queixas são menos evidentes, o que dificulta o diagnóstico precoce. ${ }^{44,45}$

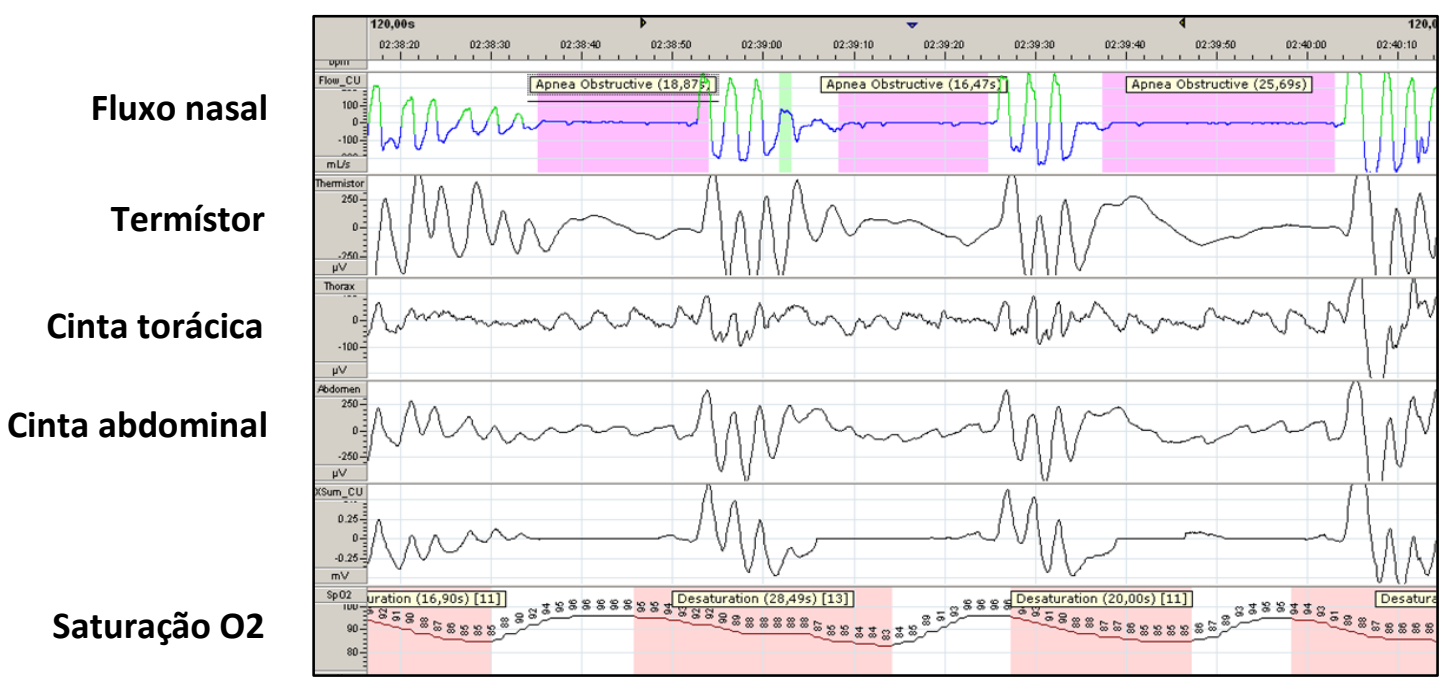

Figura 2 - Polissonografia de um paciente com apneia obstrutiva do sono. Observa-se a ausência de fluxo aéreo nasal (apneia) associada a esforço inspiratório torácico e abdominal. Curva de oximetria revela queda da saturação de oxigênio durante os episódios.

Os mecanismos através dos quais a apneia do sono obstrutiva gera dano cardiovascular envolvem: pressão intratorácica negativa exagerada com aumento da pós-carga e do estresse miocárdico transmural, hipóxia, ativação do sistema nervoso simpático e redução do tônus parassimpático, inflamação e lesão endotelial. ${ }^{46-49}$ Em conjunto, essas alterações determinam progressão da insuficiência cardíaca e arritmias malignas. ${ }^{50} \mathrm{O}$ tratamento da apneia do sono com uso de pressão positiva contínua em via aérea pode atenuar as alterações descritas, embora o impacto sobre a mortalidade de pacientes com IC ainda não tenha sido demonstrado. ${ }^{51,52}$ 


\subsubsection{Apneia central do sono e Respiração de Cheyne-Stokes (ACS-RCS)}

A ACS-RCS é uma forma de respiração periódica em que ocorre alternância entre ciclos de apneia/hipopneia centrais (isto é, sem esforço inspiratório) e períodos de hiperventilação, em um padrão crescente e decrescente de volume corrente. ${ }^{36,53} \mathrm{Na}$ maioria dos casos, a ACS-RCS é considerada uma consequência da IC avançada. Não está claro, no entanto, se é apenas um marcador de gravidade ou se determina progressão da doença cardíaca. ${ }^{36}$

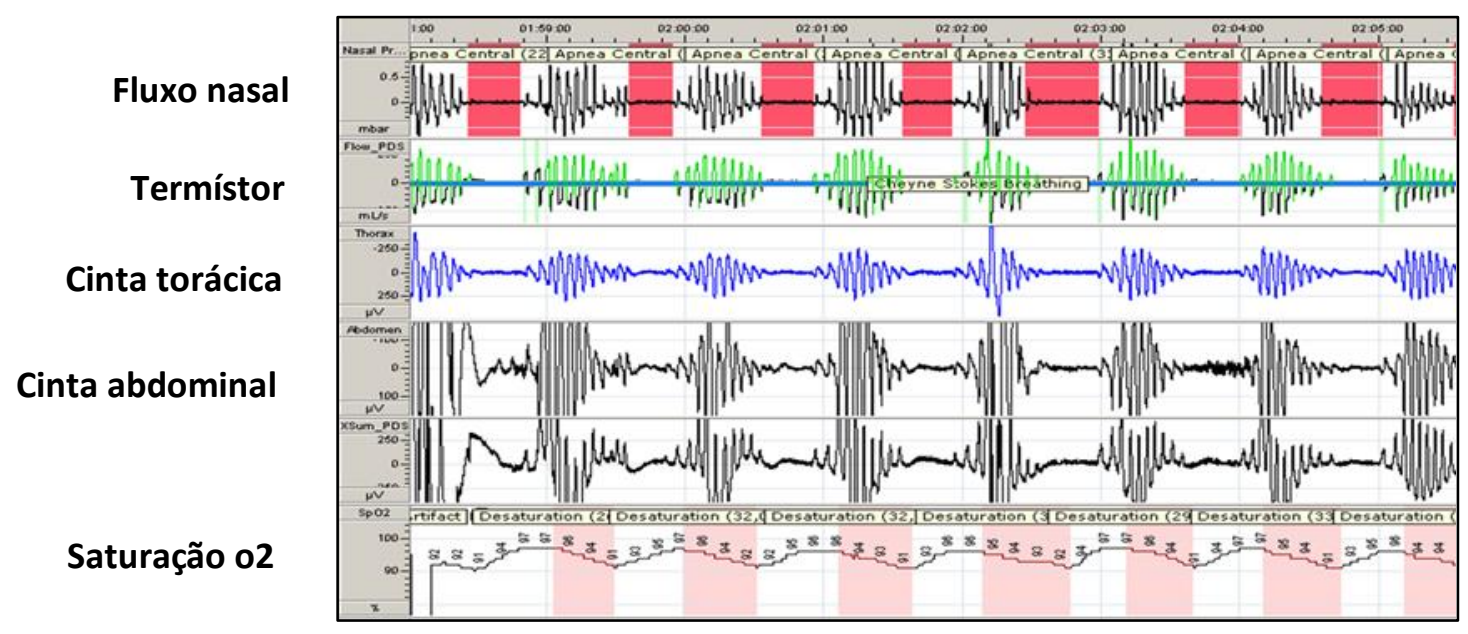

Figura 3 - Polissonografia de um paciente com apneia central e respiração de Cheyne-Stokes. Observa-se a ausência de fluxo aéreo nasal (apneia) associada à ausência de esforço inspiratório torácico ou abdominal. Curva de oximetria revela queda da saturação de oxigênio durante os episódios.

A sua fisiopatologia é complexa e envolve dois mecanismos básicos: atraso na circulação cardiopulmonar e sensibilidade aumentada dos quimiorreceptores ventilatórios às variações de $\mathrm{PaO} 2$ e $\mathrm{PaCO}$. Em pacientes com insuficiência cardíaca, o baixo débito cardíaco e a congestão pulmonar estimulam mecanorreceptores pulmonares que determinam hiperventilação e queda da PaCO2. Quando a PaCO2 cai abaixo do limiar ventilatório, ocorre a apneia central. Esta persiste até que a $\mathrm{PaCO} 2$ se eleve novamente e estimule a ventilação. Este ciclo está associado a despertares, hipóxia e ativação do sistema nervoso autônomo simpático. Esse modelo foi corroborado pelo estudo de Lorenzi-Filho em que a inalação de pequena quantidade de $\mathrm{CO} 2$ foi capaz de abolir a ASC-RCS. ${ }^{54}$ 
A ACS-RCS leva a um sono fragmentado e sonolência diurna de modo semelhante à AOS. Em pacientes com IC, tem prevalência de $30-50 \%$ e está associada a maior mortalidade. ${ }^{38,55} \mathrm{O}$ tratamento para pacientes com ACSRCS baseia-se no controle da doença cardíaca de base, uma vez que os dispositivos de pressão positiva contínua em vias aéreas não têm demonstrado redução de mortalidade. ${ }^{56,57}$

\subsection{Pericardiectomia}

Em pacientes com quadro clínico sugestivo de pericardite constritiva sem calcificação pericárdica importante e com sinais de atividade inflamatória pericárdica e sistêmica, o tratamento clínico pode ser considerado antes da indicação da cirurgia de pericardiectomia. Nesses casos, o tratamento etiológico (por exemplo, nos casos de tuberculose e colagenoses) ou com antiinflamatórios (nos casos idiopáticos) pode levar à completa reversão dos sinais de insuficiência cardíaca. ${ }^{27}$

Nos casos sintomáticos, em que não há sinais de inflamação aguda e o espessamento e calcificação pericárdica estão presentes, a pericardiectomia não deve ser adiada, pois pacientes em classe funcional avançada (III-IV da NYHA) e com longa evolução entre os sintomas e cirurgia apresentam maior mortalidade e menor benefício com o procedimento. ${ }^{5}$ Além desses, os principais preditores de desfecho são: idade, pressão sistólica de artéria pulmonar, disfunção ventricular, fibrilação atrial, hiponatremia, disfunção hepática e renal. ${ }^{5,10,58,59} \mathrm{Em}$ relação à etiologia, os pacientes com pericardite secundária (radioterapia, cirurgia cardíaca) têm pior prognóstico quando comparados àqueles com causa idiopática. ${ }^{10}$

Existem dois tipos principais de abordagem cirúrgica para ressecção do pericárdio: toracotomia anterolateral e esternotomia mediana.$^{60} \mathrm{O}$ sucesso do procedimento depende diretamente do grau de atrofia e fibrose miocárdica, assim como do grau de calcificação e adesão entre epicárdio e pericárdio que dificultam o desbridamento cirúrgico. ${ }^{61} \mathrm{~A}$ mortalidade relacionada ao procedimento varia de $6-12 \%$ e as principais complicações incluem disfunção ventricular esquerda aguda, sangramento e ruptura de parede ventricular. .,61,62 $^{-1}$ 
Apesar de o procedimento apresentar alto risco de mortalidade, os escores de risco tradicionais para cirurgia cardíaca não contemplam de forma adequada essa população. ${ }^{63,64}$ A maioria dos pacientes $(70-80 \%)$ apresenta melhora da classe funcional e a sobrevida em cinco anos pode chegar a $80 \%$, a depender da etiologia e fatores prognósticos já descritos. ${ }^{5,65,66}$

Em estudo brasileiro, realizado na Unidade Clinica de Miocardiopatias do InCor, Melo et al demonstraram que anemia, hipertensão pulmonar (PSAP > 55 $\mathrm{mmHg}$ ), e proteína c-reativa elevada se associaram a pior desfecho. Além disso, o nível sérico de BNP acima de $320 \mathrm{pg} / \mathrm{mL}$ se associou de maneira independente com mortalidade. ${ }^{7}$

\subsection{Racional do estudo}

A pericardiectomia permanece como o tratamento padrão ouro para pacientes com pericardite constritiva crônica sintomática, entretanto, o procedimento apresenta alta mortalidade e uma parcela significativa dos pacientes não apresenta melhora dos sinais e sintomas de insuficiência cardíaca. Além disso, o impacto da pericardiectomia na capacidade cardiopulmonar de pacientes com pericardite constritiva ainda é pouco estudado. ${ }^{10,65,66}$ Nesse contexto, o estudo de medidas objetivas de capacidade funcional e função cardiorrespiratória torna-se desejável, por abrir perspectivas para novos estudos que melhorem a seleção de pacientes, estratificação de risco e avaliação dos resultados da pericardiectomia nessa população. 
Objetivos 


\section{OBJETIVOS}

\subsection{Primário}

$\checkmark$ Avaliar o impacto da cirurgia de pericardiectomia sobre a capacidade funcional de pacientes com pericardite constritiva crônica sintomática.

\subsection{Secundários}

$\checkmark$ Avaliar em uma população de pacientes com pericardite constritiva crônica sintomática:

- a frequência da apneia do sono;

- o impacto da pericardiectomia sobre a apneia do sono, BNP e parâmetros do ecocardiograma;

- o impacto da pericardiectomia sobre a qualidade de vida e do sono. 
Metodologia 


\section{METODOLOGIA}

Este estudo foi desenvolvido na Unidade Clínica de Miocardiopatias e Doenças da Aorta (InCor) com financiamento da Fundação de Amparo à Pesquisa do Estado de São Paulo (FAPESP) processo número 2012/10819-4. Foi aprovado pelo Comitê de Ética para Análise de Projetos de Pesquisa (HCFMUSP) conforme parecer 202.007, SDC: 3823/12/079.

\subsection{Seleção de pacientes}

\section{Critérios de inclusão:}

A. Pacientes de ambos os sexos, idade de 18 a 70 anos;

B. Diagnóstico definido de pericardite constritiva crônica sintomática, com indicação de cirurgia de pericardiectomia.

\section{Critérios de exclusão:}

A. Obesidade: Índice de massa corporal $\left.>30 \mathrm{~kg} / \mathrm{m}^{2}\right)$;

B. Doença pulmonar grave;

C. Valvopatia cardíaca primária moderada ou grave;

D. Miocardiopatias de outras etiologias;

E. Pericardite constritiva de etiologia neoplásica.

O diagnóstico de pericardite constritiva crônica foi baseado em critérios clínicos, ecocardiográficos, nos achados de ressonância magnética cardíaca e posteriormente confirmado pela cirurgia.

\subsection{Desenho do estudo}

Trata-se de um estudo observacional prospectivo, tipo coorte. Foram avaliados os pacientes com PCC e indicação pericardiectomia internados na enfermaria da Unidade de Miocardiopatias do InCor. Após receberem orientação sobre os procedimentos do estudo, todos os pacientes assinaram o Termo de Consentimento Livre e Esclarecido (ANEXO A). Após esta etapa, foram realizados os seguintes procedimentos: 
1) Avaliação clínica e consulta aos dados do prontuário. Foram consultados todos os exames referentes à definição etiológica, estratificação de gravidade e morbidades. As variáveis avaliadas de maneira sistemática estão resumidas na ficha de avaliação (ANEXO B).

2) Avaliação antropométrica: os valores de circunferência cervical foram adquiridos pela medida realizada em nível do bordo superior da membrana cricotiróidea. A circunferência abdominal foi medida a partir da distância média entre o bordo superior da crista ilíaca e bordo inferior do último arco costal.

3) Ecocardiograma transtorácico.

4) Polissonografia noturna completa.

5) Teste de esforço cardiopulmonar.

6) Dosagem dos níveis séricos de BNP.

7) Aplicação dos questionários (ANEXOS C, D, E): Epworth (escala de sonolência diurna), Pittsburgh (qualidade do sono), Minnesota Living With Heart Failure Questionnaire adaptado para língua portuguesa (avaliação da qualidade de vida).

Após a realização dos exames, os pacientes foram submetidos à pericardiectomia conforme a rotina do serviço. Seis meses após o procedimento, todos foram convocados para repetir os mesmos procedimentos em regime ambulatorial. Não houve interferência do estudo na definição de conduta terapêutica ou investigação dos casos, que ficou exclusivamente sob a responsabilidade da equipe médica da Unidade Clínica de Miocardiopatias e Doenças da Aorta do InCor.

\subsection{Métodos complementares}

\subsubsection{Ecocardiograma transtorácico}

O estudo ecocardiográfico completo de repouso com Doppler pulsado, contínuo e em cores, foi realizado em equipamento de ultrassom Sequoia 512 (Acuson, Mountain View, California, USA), com transdutor de 2,5 MHz. Todas as medidas foram obtidas conforme as recomendações da Sociedade 
Americana de Ecocardiografia. ${ }^{11}$ Os exames foram realizados por examinador experiente e cego para os resultados dos outros exames do protocolo. Todas as imagens foram armazenadas em formato digital para posterior análise. Os pacientes foram posicionados em decúbito dorsal semilateral esquerdo, com três eletrodos no tórax para registro simultâneo do ECG e respirômetro nasal para avaliação dos movimentos respiratórios. Foram adquiridas imagens dos planos paraesternal eixo curto e longo, apical quatro e duas câmaras, além do subcostal. A partir do plano paraesternal foram obtidas as seguintes medidas: diâmetro da aorta e do átrio esquerdo, diâmetros diastólico e sistólico do ventrículo esquerdo (VE), espessura diastólica do septo interventricular e da parede posterior do VE para cálculo da massa e índice de massa do VE e o percentual de encurtamento sistólico do diâmetro do VE (Delta D\%). A partir dos planos apicais quatro e duas câmaras foram obtidos os volumes sistólico e diastólico do ventrículo esquerdo para cálculo da fração de ejeção, além das medidas do volume máximo do átrio esquerdo (no final da diástole ventricular, imediatamente antes da abertura da valva mitral), ambas pelo método Simpson. A medida do ventrículo direito foi obtida a partir do plano apical quatro câmaras, paralelamente ao anel valvar tricúspide.

As valvas tiveram suas avaliações morfológicas e funcionais realizadas pelo modo bidimensional modo-M e pelo Doppler pulsado, contínuo e colorido. Os refluxos valvares foram avaliados, semiquantitativamente, de grau I a IV.

No plano apical o Doppler pulsado foi posicionado na borda do folheto mitral para avaliar as ondas E e A, o tempo de desaceleração (TD), e a variação da onda $E$ ao longo do ciclo respiratório. A variação respiratória (\%) foi calculada com a seguinte fórmula ( $E$ expiração $-E$ inspiração) / $E$ inspiração $x$ 100. Da mesma forma, no plano subcostal o Doppler pulsado foi utilizado para medir a taxa de fluxo diastólico reverso em veias hepáticas conforme a fórmula (Velocidade diastólica reversa / Velocidade diastólica anterógrada) na expiração. ${ }^{67}$

O Doppler tecidual foi utilizado para avaliar no ânulo mitral as velocidades de relaxamento diastólico (e') medial e lateral. Os planos paraesternal e apical 
foram utilizados para detectar qualitativamente a variação respiratória do septo interventricular. O plano apical foi utilizado para avaliar a presença de distorções do contorno ventricular. A variação respiratória do diâmetro da veia cava foi avaliada pelo plano subcostal.

\subsubsection{Polissonografia noturna completa}

A polissonografia (PSG) convencional de noite inteira consiste em um sistema de registro de diversos parâmetros fisiológicos durante o sono, com a utilização de um multicanal que monitoriza, em ambiente controlado, 0 eletroencefalograma, eletrooculograma, eletromiograma, saturação de oxigênio, fluxo de ar, esforço respiratório e frequência cardíaca. Neste estudo, utilizamos o polígrafo da marca Embla (Medical Devices, Broomfield, USA). Foram monitoradas as fases do sono, quantificadas as porcentagens de cada estágio do sono, o tempo total de sono, a latência do sono, eficiência do sono e episódios de despertar. ${ }^{43}$ As mudanças no fluxo de ar foram registradas por sensor térmico sensível às variações de calor - termístor oronasal, pelo cateter nasal conectado a um transdutor de pressão e um pequeno microfone localizado na região cervical para a detecção de roncos. A saturação de oxigênio arterial foi detectada pela oximetria de pulso. As curvas de esforço respiratório do tórax e abdômen foram registradas por cintas piezoelétricas e, para frequência cardíaca, utilizamos o ECG com derivação precordial.

Apneia foi definida pela cessação completa ou redução de $90 \%$ do fluxo de ar por no mínimo 10 segundos, associado à dessaturação da oxihemoglobina em no mínimo 3\%. Hipopneia foi definida como uma redução $>50 \%$ do fluxo aéreo por no mínimo 10 segundos, associado à dessaturação da oxihemoglobina em no mínimo 3\%. O índice de apneia-hipopneia (IAH) foi obtido somando o número de apneias + hipopneias e as dividindo pelas horas de sono. Consideramos apneia leve quando encontrado um IAH entre 5 e 14,9 eventos/hora, moderada quando IAH entre 15 e 29,9 eventos/hora, e grave quando IAH $\geq 30$ eventos/hora. ${ }^{43}$ A PSG foi realizada no Laboratório do sono do InCor. 


\subsubsection{Teste de esforço cardiopulmonar}

A capacidade funcional foi avaliada com o teste de esforço cardiopulmonar (TCP) conforme recomendações da American Heart Association. ${ }^{68} \mathrm{O}$ exame consiste na realização de teste ergométrico máximo associado à avaliação de trocas gasosas. A avaliação foi realizada em esteira rolante (Ergoline - Via Sprint 150 P) com protocolo de Balke modificado com velocidade variando e 2 a $3,4 \mathrm{mph}$ e incremento de inclinação de $2 \%$ por minuto. Após posicionamento na esteira, os pacientes foram conectados a uma válvula com transdutor de volume associada à preensão nasal, além de monitorização eletrocardiográfica (Micromed - Cardio PC 13). As frações de oxigênio (O2) e dióxido de carbono (CO2) foram medidas a cada ciclo respiratório. Esta avaliação foi realizada em um sistema computadorizado (Sensormedics, Vmax Analyzer Assembly, Encore 29S). A partir das análises de ventilação pulmonar $\left(V_{E}\right)$ e das concentrações dos gases expirados foram calculados o consumo de oxigênio (VO2) e a produção de CO2 (VCO2). O VO2 pico foi considerado o consumo de oxigênio obtido no pico de exercício, quando o indivíduo se encontrava em exaustão.

Todos foram encorajados a realizar o exercício até que sintomas tais como fadiga, dispneia ou angina progressiva impedissem a continuação do teste. A presença de alterações eletrocardiográficas significativas também foi considerada para interrupção. O período de recuperação utilizado foi de seis minutos. Além do fluxo respiratório, a pressão arterial e a frequência cardíaca foram monitorizadas durante todo o teste. A pressão arterial foi avaliada pelo método auscultatório, sendo as aferições realizadas a cada dois minutos de exercício. No período de recuperação a pressão arterial foi medida no primeiro, segundo, quarto e sexto minutos. A frequência cardíaca foi continuamente monitorizada por sinal eletrocardiográfico e registrada ao final de cada minuto do período de exercício e recuperação.

O limiar anaeróbico (LA) foi definido no minuto em que o indivíduo atingiu menor valor da pressão parcial de oxigênio no final da expiração (PetO2) e do equivalente ventilatório de oxigênio (VE/VO2), antes que estes parâmetros 
aumentassem de forma não linear, ou próximo à razão de troca respiratória (RER) igual a 1,0. O ponto de compensação respiratória PCR foi determinado no minuto em que o indivíduo apresentou valor mínimo de equivalente ventilatório de $\mathrm{CO} 2\left(\mathrm{~V}_{E} / \mathrm{VCO} 2\right)$, antes que este parâmetro iniciasse um aumento progressivo, e o valor máximo de pressão parcial de CO2 no final da expiração (PetCO2), quando se iniciou uma queda progressiva desta resposta.

O teste de esforço cardiopulmonar foi considerado máximo quando o indivíduo atingia pelo menos um dos parâmetros seguintes: RER > 1,10; FC > $95 \%$ do predito para a idade; cansaço extremo.

\subsubsection{Peptídeo natriurético tipo B}

As dosagens de BNP foram realizadas utilizando kit ADVIA Centaur ${ }^{\circledR}$ (Siemens Medical Solutions Diagnostic, Los Angeles, California, USA) e processadas em equipamento automatizado da mesma marca. Trata-se de imunoensaio tipo sanduiche com tecnologia quimioluminescente e anticorpos monoclonais. As amostras foram processadas em até duas horas após a coleta, conforme recomendação do fabricante.

\subsubsection{Questionários}

\subsubsection{Escala de Sonolência de Epworth}

A Escala de Epworth foi utilizada para avaliar subjetivamente a sonolência excessiva diurna. Os pacientes foram questionados em relação à possibilidade de cochilar em 8 situações cotidianas diferentes. Cada situação foi pontuada de "zero" a 3 , sendo: "zero" = nenhuma chance de cochilar; 1 = pequena chance; 2 = moderada chance e $3=$ grande chance de cochilar. $\mathrm{O}$ escore total varia de 0 a 24 pontos e, quando acima de 9, traduz uma sonolência excessiva patológica. ${ }^{69}$ 


\subsubsection{2 Índice de Qualidade de Sono de Pittsburgh}

Avalia a qualidade do sono relacionada aos últimos trinta dias, de acordo com sete componentes: a) qualidade subjetiva do sono; b) latência do sono; c) duração do sono; d) eficiência habitual do sono; e) distúrbios do sono; f) uso de medicamentos para dormir e g) disfunção diária (a forma pela qual este distúrbio do sono interfere nas atividades de vida diárias). A soma final destes componentes pode ser interpretada da seguinte forma: 0 - 4: boa qualidade de sono; 5 - 10: má qualidade do sono e acima de 10: presença de distúrbio do sono. ${ }^{70}$

\subsubsection{Questionário Minnesota}

Para avaliação da qualidade de vida foi aplicado o questionário Minnesota Living With Heart Failure na versão validada para língua portuguesa. ${ }^{71} \mathrm{O}$ questionário consiste em 21 perguntas autoadministradas que abordam aspectos emocionais e físicos dos pacientes com insuficiência cardíaca. Cada pergunta deve ser respondida pelo paciente em escala de 0 a 5 . 0 resultado final é obtido através da soma de todas as respostas. ${ }^{72}$ Os pacientes foram encorajados a responder o questionário sem a presença de familiares e amigos e antes de outros procedimentos de intervenção, com o objetivo de reduzir vieses.

\subsection{Análise estatística e tamanho amostral}

Devido ao caráter exploratório do estudo e ausência de estudos prévios sobre o tema, não foi realizado cálculo de tamanho amostral, sendo considerada uma amostra de conveniência. Com base no histórico das pericardiectomias por PCC realizadas nos últimos 20 anos no InCor (6-10 por ano), definimos o tamanho da amostra em 25 pacientes.

Todas as variáveis foram testadas para avaliar se apresentavam distribuição normal (teste de Shapiro-Wilk). As variáveis contínuas com distribuição normal foram expressas em média \pm DP. Nos casos com 
distribuição não normal utilizamos a mediana (intervalo interquartil). As variáveis categóricas foram expressas em número absoluto e porcentagem. A comparação entre grupos no pré-operatório foi realizada com teste $T$ não pareado (distribuição normal) ou Mann-Whitney (distribuição não normal) para as variáveis contínuas e teste exato de Fisher para as variáveis categóricas. As variáveis pré e pós-operatórias foram comparadas utilizando o teste $T$ pareado (distribuição normal) ou teste de Wilcoxon (distribuição não normal). As correlações entre as variáveis foram realizadas utilizando o método de Spearman ou Pearson, quando apropriado.

Para avaliação dos preditores de melhora da capacidade funcional após a pericardiectomia utilizamos análise multivariada com a variação do VO2 predito como variável dependente $(\Delta \mathrm{VO} 2 \%=\mathrm{VO} 2$ pico predito pós $-\mathrm{VO} 2$ pico predito pré). Selecionamos inicialmente entre as características basais (préoperatórias) os parâmetros na análise univariada com $p<0,10$. Em seguida, realizamos modelo de regressão linear multivariado com processo de seleção stepwise para identificar preditores independentes de melhora do VO2 pico predito. As análises foram realizadas com o software SPSS Statistics 17.0 (SPSS Inc., Chicago, Illinois, EUA). O valor de $p<0.05$ foi considerado estatisticamente significante. 
Resultados 


\section{RESULTADOS}

\subsection{Dados gerais}

No período de fevereiro de 2011 a Setembro de 2015 foram selecionados 36 pacientes, sendo que 33 pacientes preencheram os critérios de inclusão. Oito pacientes preencheram critérios de exclusão ou desistiram do estudo, sendo considerados para análise final 25 pacientes (Figura 4).

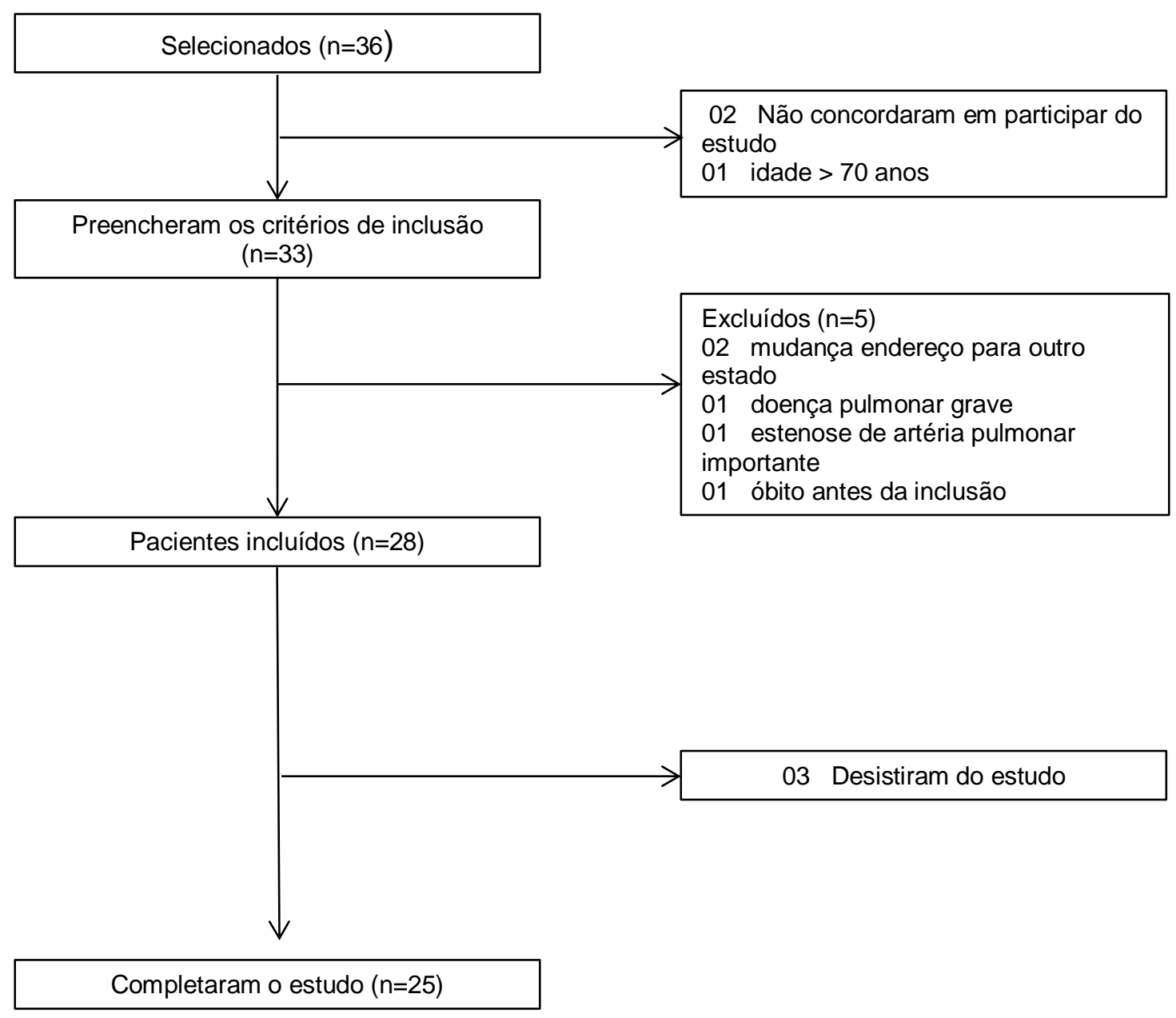

Figura 4 - Fluxograma do estudo.

As características clínicas e laboratoriais pré-operatórias dos pacientes estão resumidas na Tabela 3. 
Tabela 3 - Características clínicas e laboratoriais pré-operatórias

\begin{tabular}{|c|c|}
\hline Parâmetro & Valor $(n=25)$ \\
\hline Idade (anos) & $45,5 \pm 13,8$ \\
\hline Sexo masculino, n (\%) & $19(76)$ \\
\hline IMC $\left(\mathrm{kg} / \mathrm{m}^{2}\right)$ & $24,9 \pm 3,7$ \\
\hline Circunferência cervical (cm) & $37(36-38,3)$ \\
\hline Cintura abdominal (cm) & $93,6 \pm 8,7$ \\
\hline \multicolumn{2}{|l|}{ Etiologia } \\
\hline Idiopática, n (\%) & $19(76)$ \\
\hline Tuberculose, n (\%) & $3(12)$ \\
\hline Pós-operatório, n (\%) & $1(4)$ \\
\hline Doença inflamatória sistêmica, $\mathrm{n}(\%)$ & $2(8)$ \\
\hline Tempo de sintomas (meses) & $24(12-36)$ \\
\hline Classe funcional NYHA III/ IV, n (\%) & $14(56)$ \\
\hline Ascite, $\mathrm{n}(\%)$ & $18(72)$ \\
\hline Edema de membros inferiores, $\mathrm{n}(\%)$ & $22(88)$ \\
\hline \multicolumn{2}{|l|}{ Ressonância cardíaca } \\
\hline FEVE (\%) & $58 \pm 11$ \\
\hline Espessura pericárdio (mm) & $7,2 \pm 3,6$ \\
\hline Bounce septal, n (\%) & $23(92)$ \\
\hline Dilatação de veia cava inferior, n (\%) & $23(92)$ \\
\hline EuroSCORE logístico (\%)* & $0,9(0,8-1,2)$ \\
\hline Hipertensão, n (\%) & $4(16)$ \\
\hline Diabetes, n (\%) & $2(8)$ \\
\hline Tabagismo, n (\%) & $5(20)$ \\
\hline Fibrilação atrial, n (\%) & $10(40)$ \\
\hline Furosemida (mg) & $40(30-80)$ \\
\hline Espironolactona (mg) & $25(0-62,5)$ \\
\hline $\mathrm{BNP}(\mathrm{pg} / \mathrm{mL})$ & $143(83,5-209,5)$ \\
\hline PCR (mg/dL) & $5,4(3-10)$ \\
\hline Creatinina (mg/dL) & $1(1-1,2)$ \\
\hline Hemoglobina (g/dL) & $13,7 \pm 2$ \\
\hline
\end{tabular}

Dados com distribuição normal foram apresentados com média \pm desvio padrão. Dados com distribuição anormal foram apresentados como mediana e intervalo interquartil. * Expressa em porcentagem o risco de morte pós-operatória calculado pelo EuroSCORE. IMC: índice de massa corporal; NYHA: New York Heart Association; FEVE: fração de ejeção do ventrículo esquerdo; BNP: peptídeo natriurético tipo B; PCR: proteína c-reativa.

A idade média foi 45 anos, com predomínio do sexo masculino. A etiologia predominante foi idiopática, seguida por tuberculose. A maioria dos pacientes 
apresentou sintomas limitantes e sinais clínicos de hipervolemia a despeito do tratamento clínico medicamentoso. A ressonância cardíaca revelou função ventricular preservada e pericárdio espessado. Seis pacientes apresentaram realce tardio pelo gadolínio no pericárdio e dois pacientes no miocárdio. Calcificação pericárdica foi identificada na radiografia de tórax de onze pacientes (44\%).

Todos os pacientes foram submetidos à pericardiectomia de frênico a frênico via esternotomia mediana, sem uso de circulação extracorpórea. O plano de ressecção foi estendido até a face diafragmática do coração. Quando possível, foi realizada a ressecção do pericárdio visceral e parietal. Em três casos a ressecção foi considerada incompleta pela presença de extensa calcificação e aderência ao epicárdio. Dois pacientes foram submetidos à cirurgia de revascularização concomitante pela presença de lesão obstrutiva significativa em descendente anterior e coronária direita anômala. Os pósoperatório foi realizado na UTI Cirúrgica do InCor, com média de permanência de $3,4 \pm 3,3$ dias. Dois pacientes tiveram o tempo de UTI prolongado pela presença de choque cardiogênico secundário a síndrome de descompressão pericárdica, revertida após medidas de suporte com inotrópicos. Após a alta hospitalar, que ocorreu em média no $12^{\circ}$ dia de pós-operatório, todos os pacientes realizaram seguimento no ambulatório em 15, 90 e 180 dias conforme rotina do serviço. Durante esse período, dois pacientes foram readmitidos no hospital devido insuficiência cardíaca descompensada. Em um dos casos, foi realizada nova cirurgia via esternotomia mediana para drenagem de coleção mediastinal de aspecto seroso com sinais de compressão do ventrículo direito. No segundo caso, o quadro foi controlado com ajuste do tratamento clínico medicamentoso.

\subsection{Efeito da pericardiectomia sobre características clínicas e qualidade} de vida

Como pode ser observado na Tabela 4 e Figura 5, a cirurgia de pericardiectomia determinou mudanças significativas no quadro clínico e 
laboratorial da maioria dos pacientes. Observou-se redução dos sinais de congestão sistêmica e circunferência abdominal, com menor necessidade do uso de diuréticos no pós-operatório (Tabela 5). A despeito disso, o peso praticamente não se alterou. De fato, observamos que a maioria dos pacientes teve a perda de líquidos compensada por ganho de massa magra/gordura ao longo dos seis meses de acompanhamento. Ocorreu também redução dos níveis séricos de BNP e da proteína c-reativa. Além disso, no pré-operatório 56 $\%$ dos pacientes estavam em classe funcional III-IV com redução para $8 \%$ após a cirurgia.

Tabela 4 - Efeito da pericardiectomia nos parâmetros antropométricos, clínicos e laboratoriais

\begin{tabular}{|c|c|c|c|}
\hline Parâmetro & Pré $(n=25)$ & Pós $(n=25)$ & $p$ \\
\hline \multicolumn{4}{|l|}{ Antropométricos } \\
\hline Peso $(\mathrm{Kg})$ & $73,9 \pm 14$ & $74,2 \pm 16$ & 0,722 \\
\hline $\mathrm{IMC}\left(\mathrm{kg} / \mathrm{m}^{2}\right)$ & $24,9 \pm 3,7$ & $25,5 \pm 3,9$ & 0,181 \\
\hline Circunferência cervical $(\mathrm{cm})$ & $37(36-38,3)$ & $37,3(36-37,7)$ & 0,360 \\
\hline Circunferência abdominal (cm) & $93,6 \pm 8,7$ & $89,04 \pm 8,7$ & 0,002 \\
\hline \multicolumn{4}{|l|}{ Clínicos } \\
\hline $\mathrm{FC}(\mathrm{bpm})$ & $76(70,5-83,5)$ & $71(66-76)$ & 0,091 \\
\hline PA sistólica $(\mathrm{mmHg})$ & $110(100-125)$ & $110(100-120)$ & 0,588 \\
\hline PA diastólica $(\mathrm{mmHg})$ & $70(60-75)$ & $66(60-73)$ & 0,438 \\
\hline Turgência jugular 45으. n (\%) & $22(88)$ & $10(40)$ & $<0,001$ \\
\hline Ascite, $\mathrm{n}(\%)$ & $18(72)$ & $3(12)$ & $<0,001$ \\
\hline Edema MMII, n (\%) & $22(88)$ & $6(24)$ & $<0,001$ \\
\hline \multicolumn{4}{|l|}{ Laboratoriais } \\
\hline $\mathrm{BNP}(\mathrm{pg} / \mathrm{mL})$ & $143(83,5-209,5)$ & $76(40-117,5)$ & 0,011 \\
\hline Proteína c-reativa (mg/dL) & $5,4(3-10)$ & $2,5(1,8-4,5)$ & 0,014 \\
\hline Hemoglobina (g/dL) & $13,7 \pm 2$ & $14,3 \pm 2,2$ & 0,138 \\
\hline Creatinina (mg/dL) & $1(1-1,2)$ & $0,9(0,8-1)$ & 0,007 \\
\hline
\end{tabular}

Dados com distribuição normal foram apresentados com média \pm desvio padrão. Dados com distribuição anormal foram apresentados como mediana e intervalo interquartil. IMC: índice de massa corpórea; FC: frequência cardíaca; PA: pressão arterial; MMII: membros inferiores; BNP: peptídeo natriurético tipo $\mathrm{B}$. 


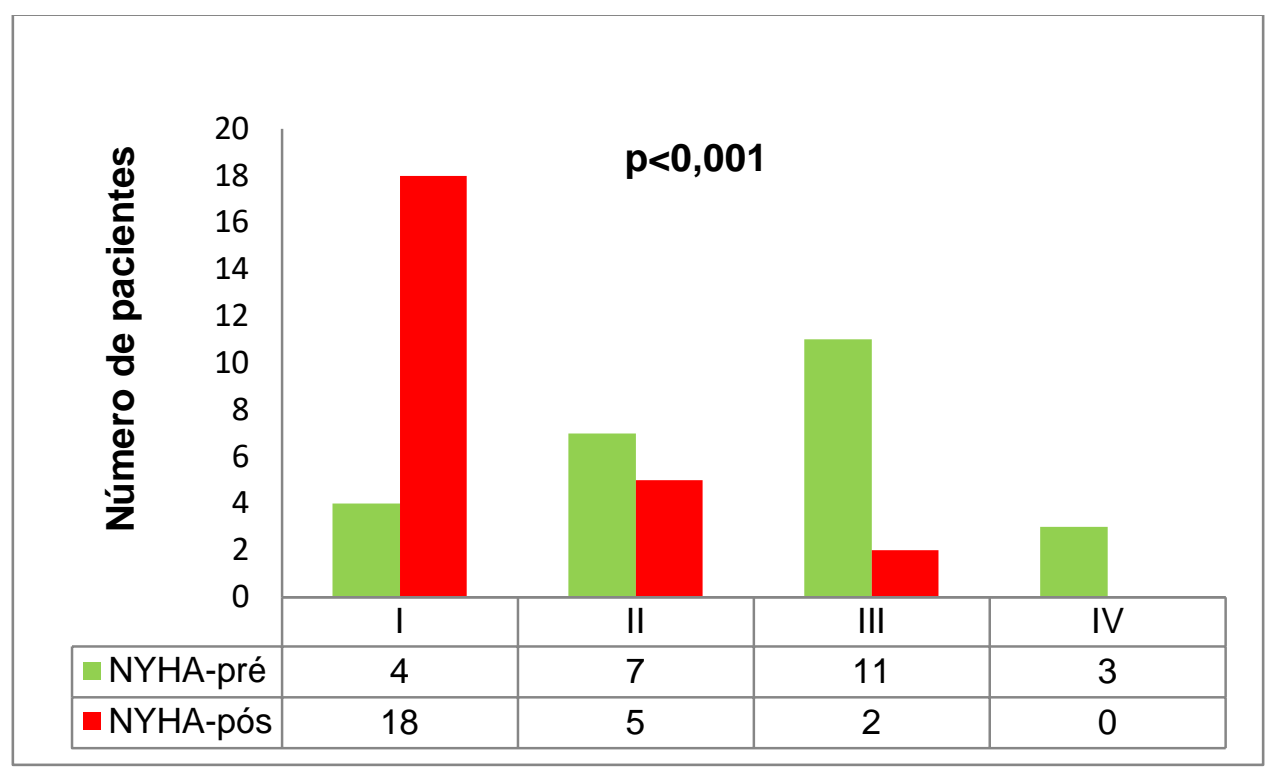

Figura 5 - Melhora da classe funcional New York Heart Association após pericardiectomia.

Tabela 5 - Comparação das medicações utilizadas no pré e pós-operatório

\begin{tabular}{lccc}
\hline Medicamentos & Pré $(\mathbf{n}=\mathbf{2 5})$ & Pós $(\mathbf{n = 2 5})$ & $\boldsymbol{p}$ \\
\hline Furosemida $(\mathrm{mg})$ & $56 \pm 50$ & $26,4 \pm 37,7$ & $\mathbf{0 , 0 2 1}$ \\
Espironolactona $(\mathrm{mg})$ & $25(0-62,5)$ & 0 & $\mathbf{0 , 0 0 2}$ \\
Betabloqueador, n (\%) & $6(24)$ & $11(44)$ & 0,095 \\
Amiodarona, n (\%) & $3(12)$ & $4(16)$ & 0,563 \\
IECA/BRA, n (\%) & $4(16)$ & $3(12)$ & 0,563 \\
Varfarina, $\mathrm{n}(\%)$ & $8(32)$ & $8(32)$ & 1,00 \\
\hline
\end{tabular}

Dados com distribuição normal foram apresentados com média \pm desvio padrão. Dados com distribuição anormal foram apresentados como mediana e intervalo interquartil. IECA: inibidor da enzima conversora de angiotensina; BRA: bloqueador do receptor de angiotensina.

A melhora dos sintomas dos pacientes foi acompanhada de melhora da qualidade de vida (Tabela 6). Em apenas dois pacientes não houve redução do escore. Esses dois casos permaneceram em classe funcional III após o procedimento. 
Tabela 6 - Efeito da pericardiectomia sobre a qualidade de vida

\begin{tabular}{lccc}
\hline Minnesota & Pré $(\mathbf{n}=\mathbf{2 5})$ & Pós $(\mathbf{n}=25)$ & $\boldsymbol{p}$ \\
\hline Escore total & $62(43,5-77,5)$ & $18(8,5-22)$ & $<0,001$ \\
Sintomas físicos & $26(22,5-30)$ & $8(3,50-10)$ & $<0,001$ \\
Sintomas emocionais & $12(9-17)$ & $2(0-8)$ & $<0,001$ \\
\hline
\end{tabular}

Dados foram apresentados como mediana e intervalo interquartil.

\subsection{Ecocardiograma}

Os dados do ecocardiograma estão resumidos na tabela 7. Os exames foram realizados com dificuldade técnica em virtude da janela acústica desfavorável e distorção na topografia do coração em dez casos. Além disso, a presença de fibrilação atrial em $40 \%$ dos casos limitou a avaliação de parâmetros da função diastólica.

De modo geral, os pacientes apresentaram no pré-operatório fração de ejeção biventricular preservada, aumento do átrio esquerdo e dilatação de veia cava inferior com pouca variação respiratória. A variação respiratória do movimento septal foi identificada em 17 pacientes. Os parâmetros de Doppler tecidual revelaram e' normal, com relação e'septal/e'lateral compatível com annulus reversus em 17 pacientes (73,9\%). Em 12 pacientes, observamos distorção do contorno de VE/VD. Derrame pericárdico foi identificado em sete pacientes, sendo discreto $(<5 \mathrm{~mm})$ em seis e moderado em um caso $(16 \mathrm{~mm})$. A avaliação das valvas cardíacas revelou insuficiência tricúspide moderada/importante em dois casos, sem outros achados relevantes.

Após a pericardiectomia, não houve alteração significativa da função ventricular ou volume atrial. Houve aumento significativo da variação respiratória da veia cava inferior e do diâmetro diastólico do VE. Em 8 pacientes, observamos distorção do contorno de VE e/ou VD. Derrame pericárdico foi identificado em cinco pacientes, sendo discreto $(<5 \mathrm{~mm})$ em quatro e moderado em um caso (14 mm). 
Tabela 7 - Comparação do ecocardiograma no pré e pós-operatório

\begin{tabular}{|c|c|c|c|}
\hline Parâmetro & Pré $(n=23)$ & Pós $(n=23)$ & $p$ \\
\hline FC (bpm) & $71,8 \pm 12$ & $76,6 \pm 15,3$ & 0,267 \\
\hline Aorta $(\mathrm{mm})$ & $30,2 \pm 3,10$ & $31,6 \pm 4,5$ & 0,090 \\
\hline Átrio esquerdo (mm) & $45(38-49)$ & $42(37-52)$ & 0,676 \\
\hline Volume $A E$ indexado $\left(\mathrm{mL} / \mathrm{m}^{2}\right)^{1}$ & $31,5(24-38,7)$ & $31(26,4-38,6)$ & 0,687 \\
\hline Área átrio direito $\left(\mathrm{cm}^{2}\right)^{2}$ & $17,5(15,1-23,4)$ & $18,3(14,8-23,8)$ & 0,396 \\
\hline DDVE (mm) & $43,2 \pm 5,1$ & $47 \pm 5,3$ & 0,001 \\
\hline DSVE (mm) & $29,5 \pm 4,2$ & $31,1 \pm 4,5$ & 0,132 \\
\hline DDVD basal (mm) & $27,5(26-32)$ & $32(28-36)$ & 0,036 \\
\hline Volume diastólico VE (mL) & $60(51-64)$ & $68(52-81)$ & 0,132 \\
\hline Volume sistólico VE (mL) & $22(19-26)$ & $25(21-30)$ & 0,112 \\
\hline FEVE Simpson (\%) & $60 \pm 6$ & $60 \pm 4$ & 0,661 \\
\hline $\operatorname{TRIV}(\mathrm{ms})^{3}$ & $95,2 \pm 25$ & $92,7 \pm 16,8$ & 0,703 \\
\hline Tempo de desaceleração (ms) & $148,9 \pm 29,6$ & $168,1 \pm 38,9$ & 0,096 \\
\hline E mitral inspiração $(\mathrm{cm} / \mathrm{s})$ & $65,7 \pm 22,7$ & $70,7 \pm 22,4$ & 0,291 \\
\hline E mitral expiração $(\mathrm{cm} / \mathrm{s})$ & $84,1 \pm 27,7$ & $86,5 \pm 24,4$ & 0,625 \\
\hline $\begin{array}{l}\text { Variação respiratória do septo } \\
\text { interventricular, } \mathrm{n}(\%)\end{array}$ & $17(73,9)$ & $11(47,8)$ & 0,065 \\
\hline Variação respiratória onda E (\%) & $22,1 \pm 6,8$ & $18,8 \pm 8,3$ & 0,139 \\
\hline e' septal $(\mathrm{cm} / \mathrm{s})$ & $15,1 \pm 3,2$ & $11,1 \pm 2,5$ & $<0,001$ \\
\hline $\mathrm{e}^{\prime}$ lateral $(\mathrm{cm} / \mathrm{s})$ & $14(11-17)$ & $12(10-15)$ & 0,303 \\
\hline $\begin{array}{l}\text { Variação respiratória da veia } \\
\text { cava inferior (\%) }\end{array}$ & $12 \pm 9$ & $19,4 \pm 7,8$ & $<0,001$ \\
\hline $\begin{array}{l}\text { Veia hepática fluxo diastólico reverso } \\
\text { expiração }(\mathrm{cm} / \mathrm{s})^{4}\end{array}$ & $17,7 \pm 7,3$ & $22,3 \pm 6,9$ & 0,097 \\
\hline $\begin{array}{l}\text { Veia hepática fluxo diastólico anterógrado } \\
\text { expiração }(\mathrm{cm} / \mathrm{s})^{5}\end{array}$ & $25(22-33)$ & $30(23-43)$ & 0,140 \\
\hline $\begin{array}{l}\text { Veia hepática fluxo diastólico expiratório } \\
\text { reverso/anterógrado }\end{array}$ & $0,68 \pm 0,2$ & $0,70 \pm 0,2$ & 0,842 \\
\hline PSAP $(\mathrm{mmHg})$ & $33 \pm 8,7$ & $34,9 \pm 10,8$ & 0,577 \\
\hline
\end{tabular}

Dados com distribuição normal foram apresentados com média \pm desvio padrão. Dados com distribuição anormal foram apresentados como mediana e intervalo interquartil. FC: frequência cardíaca; AE: átrio esquerdo; DDVE: diâmetro diastólico do ventrículo esquerdo; DSVE: diâmetro sistólico do ventrículo esquerdo; DDVD: diâmetro diastólico do ventrículo direito; FEVE: fração de ejeção do ventrículo esquerdo; VD: ventrículo direito; TRIV: tempo de relaxamento isovolumétrico; PSAP: pressão sistólica de artéria pulmonar. ${ }^{1} n=18 ;{ }^{2} n=18 ;{ }^{3} n=15$; ${ }^{4} \mathrm{n}=16 ;{ }^{5} \mathrm{n}=16$. 


\subsection{Teste de esforço cardiopulmonar}

Os resultados do teste cardiopulmonar estão resumidos na tabela 8.0 exame se mostrou seguro e transcorreu sem complicações graves em todos os casos. Os testes foram considerados eficazes pela presença da mediana da razão de troca respiratória de 1,1 em ambos os momentos do estudo. Em um paciente o teste foi interrompido pela presença de taquicardia ventricular não sustentada no pico do esforço, sem sinais de instabilidade. Pela presença de sintomas limitantes em repouso, dois pacientes não realizaram o exame no pré-operatório. No pós-operatório, um paciente não realizou o exame pela presença de flutter atrial de alta resposta ventricular.

Tabela 8 - Comparação do teste de esforço cardiopulmonar no pré e pós-operatório

\begin{tabular}{lccc}
\hline Parâmetro & Pré $(\mathbf{n = 2 3})$ & Pós $(\mathbf{n = 2 3})$ & $\boldsymbol{p}$ \\
\hline Velocidade (mph) & $2,5(2-2,5)$ & $3(2,5-3,3)$ & $\mathbf{0 , 0 0 1}$ \\
Duração do teste (min) & $11 \pm 3,1$ & $11,9 \pm 1,9$ & 0,166 \\
Tempo de exercício (min) & $8,9 \pm 3,1$ & $9,8 \pm 1,9$ & 0,166 \\
Inclinação máxima (graus) & $14(8,5-18)$ & $16(12-16)$ & 0,108 \\
LA-VO2 (mL/kg/min) & $13,1 \pm 3$ & $17,7 \pm 5,5$ & $<\mathbf{0 , 0 0 1}$ \\
LA (\%) & $70,7 \pm 11,3$ & $70,5 \pm 9,3$ & 0,953 \\
PCR-VO2 (mL/kg/min) & $16,6 \pm 3,7$ & $23,1 \pm 5$ & 0,001 \\
PCR (\%)* & $89,6 \pm 4$ & $92,4 \pm 6,3$ & 0,382 \\
FC máxima (bpm) & $136,4 \pm 29,9$ & $157,3 \pm 26,5$ & $\mathbf{0 , 0 0 2}$ \\
VO2 pico (mL/kg/min) & $18,7 \pm 5,6$ & $25,2 \pm 6,3$ & $<\mathbf{0 , 0 0 1}$ \\
VO2 pico (\%) & $61,7 \pm 18,9$ & $83,6 \pm 24,7$ & $<\mathbf{0 , 0 0 1}$ \\
V $_{E}(\mathrm{~L} / \mathrm{min})$ & $50,4 \pm 13,8$ & $61,1 \pm 19,7$ & $<\mathbf{0 , 0 0 1}$ \\
RER & $1,1(1,0-1,2)$ & $1,1(1,1-1,2)$ & 0,224 \\
$V_{E} /$ VO2 & $37(33,2-42,8)$ & $33(29-3,7)$ & $\mathbf{0 , 0 0 5}$ \\
V $_{E} /$ VCO2 slope & $32,7 \pm 5,9$ & $27,06 \pm 6,5$ & $\mathbf{0 , 0 0 1}$ \\
\hline
\end{tabular}

* Representam a porcentagem em relação ao predito para idade e sexo. Dados com distribuição normal foram apresentados com média \pm desvio padrão. Dados com distribuição anormal foram apresentados como mediana e intervalo interquartil. LA-VO2: consumo de oxigênio no limiar anaeróbico; LA: limiar anaeróbico; PCR-VO2: consumo de oxigênio no ponto de compensação respiratória; PCR: ponto de compensação respiratória; FC: frequência cardíaca; VO2: consumo de oxigênio; $V_{E}$ : ventilação pulmonar; RER: razão de troca respiratória; VE/VO2: equivalente respiratório de oxigênio; $\mathrm{V}_{E} / \mathrm{VCO}$ slope: inclinação da curva de ventilação pela produção de dióxido de carbono. 
De modo geral, os pacientes apresentaram melhora da capacidade cardiopulmonar após a intervenção cirúrgica. Houve significativo aumento da velocidade da esteira rolante, do limiar anaeróbico, VO2 pico e ventilação pulmonar no pós-operatório. Em apenas um caso ocorreu piora do VO2 pico (esse paciente teve a ressecção do pericárdio considerada incompleta pela presença de intensa calcificação).

No pré-operatório, o VO2 pico predito para idade apresentou correlação inversa com o escore de qualidade de vida (Figura 6).

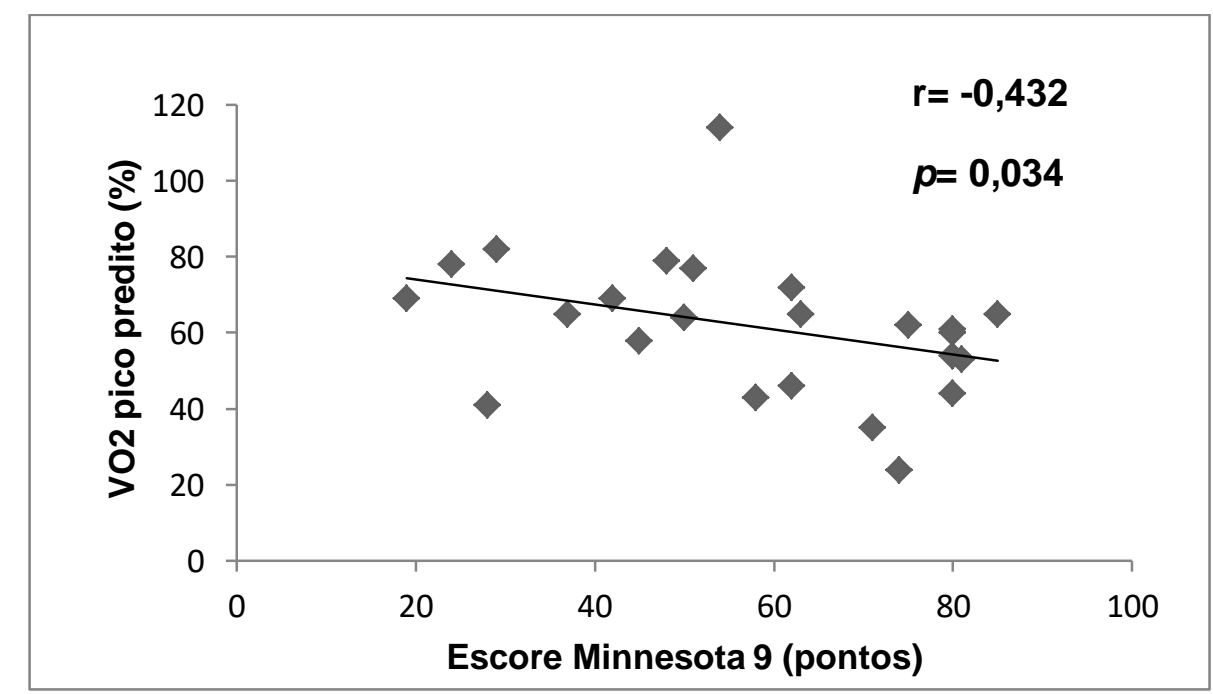

Figura 6 - Correlação entre VO2 pico predito e qualidade de vida no pré-operatório.

\subsection{Polissonografia noturna completa e questionários do sono}

A apneia do sono ( $\mathrm{IAH} \geq 5$ eventos/hora) foi diagnosticada em 23 pacientes (92\%) no pré-operatório, com predomínio de hipopneias. Desses, sete apresentaram apneia moderada e seis pacientes apresentaram apneia grave. No pré e pós-operatório foram obtidos resultados semelhantes em relação ao $\mathrm{IAH}$, tempo total de sono, eficiência e arquitetura do sono. Também não houve diferenças em relação aos despertares e episódios de hipoxemia (Tabela 9). 
A escala de sonolência de Epworth não apresentou diferenças nos seus índices no pré e pós-operatório. Por outro lado, o índice de qualidade do sono de Pittsburgh apresentou redução estatisticamente significante, refletindo a melhora na qualidade do sono dos pacientes após a cirurgia.

No período pré-operatório o IAH apresentou correlação positiva com EuroSCORE ( $r=0,480 ; p=0,015)$ e com níveis séricos de BNP (Figura 7).

Tabela 9 - Comparação do estudo do sono no pré e pós-operatório

\begin{tabular}{lccc}
\hline Parâmetro & Pré (n=25) & Pós (n=25) & $\boldsymbol{p}$ \\
\hline Epworth & $7,6 \pm 3,6$ & $6,5 \pm 4,3$ & 0,239 \\
Pittsburgh & $7,8 \pm 4,1$ & $4,7 \pm 3,7$ & $<0,001$ \\
TTS (min) & $350(323-388,7)$ & $368(347,2-398,2)$ & 0,199 \\
Eficiência do sono (\%) & $91,7(87,2-95,8)$ & $90,5(76,6-92,6)$ & 0,086 \\
N1 (\%) & $9,3(6,3-16,2)$ & $8,4(5,8-13,6)$ & 0,503 \\
N2 (\%) & $55,4(46,8-61,3)$ & $48,5(42,3-59,3)$ & 0,475 \\
N3 (\%) & $17,4 \pm 9,2$ & $15 \pm 6,9$ & 0,309 \\
REM (\%) & $16 \pm 7,9$ & $15,6 \pm 5,8$ & 0,840 \\
IAH (eventos/h) & $15,6(8,3-31,7)$ & $14,6(5,8-29,9)$ & 0,253 \\
Obstrutiva & $0,8(0-1,4)$ & $0,5(0-3,4)$ & 0,217 \\
Central & $0,2(0-1,4)$ & $0,2(0-0,7)$ & 0,138 \\
Mista & $0(0-0,4)$ & $0(0-0,2)$ & 0,610 \\
Hipopneias & $9,8(6,35-20,1)$ & $10,8(4,9-16,6)$ & 0,278 \\
SpO2 média (\%) & $94,4 \pm 1,9$ & $94,8 \pm 1,6$ & 0,321 \\
SpO2 mínima (\%) & $85,6 \pm 4,7$ & $85,5 \pm 4,6$ & 0,689 \\
Tempo SpO2<90\% (min) & $0,7(0-6,1)$ & $0,9(0-3,7)$ & 0,862 \\
\hline
\end{tabular}

Dados com distribuição normal foram apresentados com média \pm desvio padrão. Dados com distribuição anormal foram apresentados como mediana e intervalo interquartil. TTS: tempo total de sono; REM: rapid eye movement; IAH: índice de apneia-hipopneia; SpO2: saturação periférica de oxigênio. 


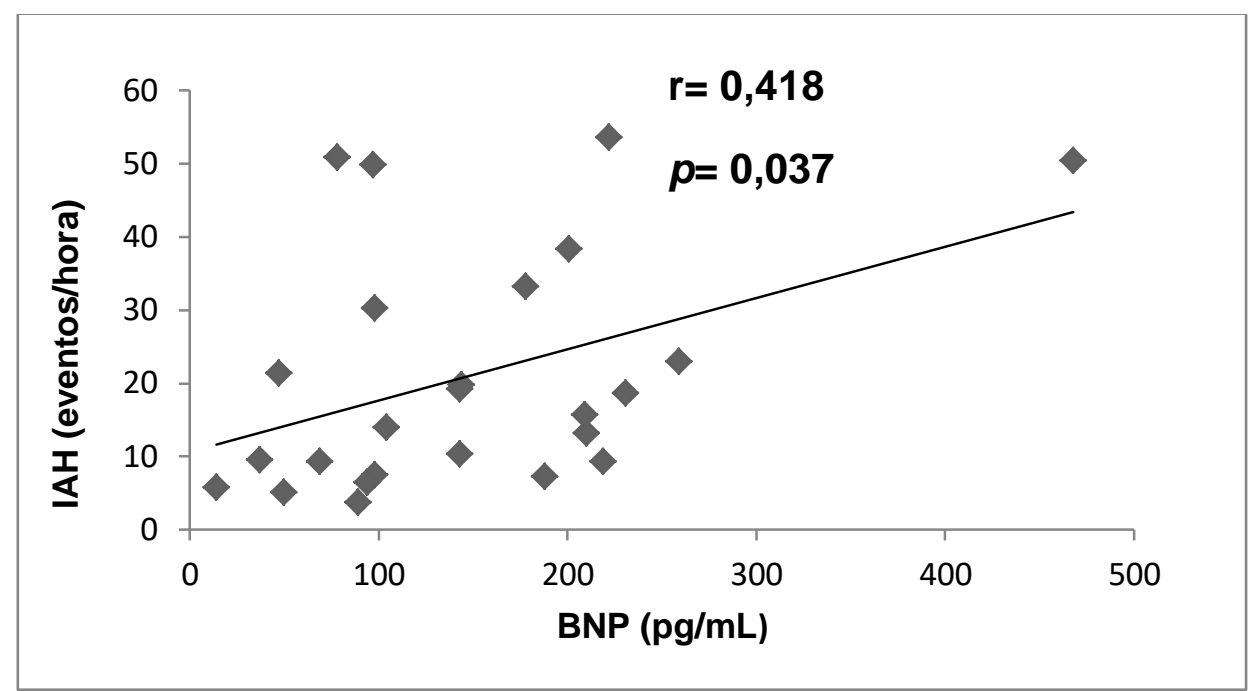

Figura 7 - Correlação entre o índice de apneia-hipopneia e níveis séricos de BNP no préoperatório.

\subsection{Comparação dos pacientes com e sem apneia moderada/grave}

No período pré-operatório, realizamos a comparação entre os grupos de pacientes com apneia moderada/grave ( $\mathrm{IH} \mathrm{H} \geq 15$ eventos /hora) e sem apneia/ apneia leve (IAH $<15$ eventos/hora). Os grupos apresentaram características semelhantes em relação à idade, sexo, IMC, etiologia, dados clínicos e laboratoriais (Tabela 10). Da mesma forma, os parâmetros ecocardiográficos não revelaram diferenças significativas. Entretanto, na análise do teste cardiopulmonar, os pacientes com apneia do sono apresentaram menor velocidade da esteira rolante, menor limiar anaeróbico e maior valor de equivalente respiratório de oxigênio (Tabela 11). 
Tabela 10 - Comparação dos dados clínicos de pacientes com e sem apneia moderada/grave

\begin{tabular}{|c|c|c|c|}
\hline Parâmetro & Sem apneia $(n=12)$ & Com apneia $(n=13)$ & $p$ \\
\hline Idade (anos) & $41 \pm 15,2$ & $49,6 \pm 11,5$ & 0,122 \\
\hline Sexo masculino, n (\%) & $7(58,3)$ & $12(92,3)$ & 0,073 \\
\hline Peso (Kg) & $73,8 \pm 17,3$ & $73,9 \pm 10,8$ & 0,987 \\
\hline $\mathrm{IMC}\left(\mathrm{kg} / \mathrm{m}^{2}\right)$ & $25,1 \pm 4,1$ & $24,8 \pm 3,4$ & 0,830 \\
\hline Circunferência cervical (cm) & $36,5(32-38,3)$ & $37,5(37-38,5)$ & 0,165 \\
\hline Circunferência abdominal $(\mathrm{cm})$ & $93 \pm 9,6$ & $94,8 \pm 7,9$ & 0,729 \\
\hline Turgência jugular 45ํ, n (\%) & $11(91,7)$ & $11(84,6)$ & 1,000 \\
\hline Ascite, n (\%) & $8(66,7)$ & $10(76,9)$ & 0,673 \\
\hline Edema MMII, n (\%) & $11(91,7)$ & $11(84,6)$ & 1,000 \\
\hline FEVE (\%) & $62 \pm 7$ & $58 \pm 11$ & 0,276 \\
\hline BNP (pg/mL) & $96(59,5-165,5)$ & $178(98-222)$ & 0,073 \\
\hline Proteína c-reativa (mg/dL) & $7,51(4,6-11,1)$ & $4,01(2,5-7)$ & 0,155 \\
\hline Hemoglobina (g/dL) & $14,1 \pm 1,3$ & $13,44 \pm 2,5$ & 0,466 \\
\hline Creatinina (mg/dL) & $0,97(0,9-1,1)$ & $1,25(1,0-1,3)$ & 0,019 \\
\hline
\end{tabular}

Dados com distribuição normal foram apresentados com média \pm desvio padrão. Dados com distribuição anormal foram apresentados como mediana e intervalo interquartil. IMC: índice de massa corpórea; MMII: membros inferiores; FEVE: fração de ejeção do ventrículo esquerdo; BNP: peptídeo natriurético tipo B.

Tabela 11 - Comparação do teste cardiopulmonar de esforço de pacientes com e sem apneia moderada/grave

\begin{tabular}{lccc}
\hline Parâmetro & Sem apneia $(\mathbf{n}=\mathbf{1 2})$ & Com apneia $(\mathbf{n}=\mathbf{1 3})$ & $\boldsymbol{p}$ \\
\hline Velocidade (mph) & $2,5(2,5-3)$ & $2,5(2-2,5)$ & $\mathbf{0 , 0 3 0}$ \\
Duração do teste (min) & $10,4 \pm 3,1$ & $11,6 \pm 3,3$ & 0,515 \\
Tempo de exercício (min) & $8,7 \pm 3,1$ & $9,59 \pm 3,3$ & 0,526 \\
Inclinação máxima (graus) & $12(7-17)$ & $15(10-18)$ & 0,425 \\
LA-VO2 (mL/kg/min) & $14,4 \pm 3$ & $12 \pm 2,5$ & $\mathbf{0 , 0 4 7}$ \\
FC máxima (bpm) & $146,6 \pm 28,6$ & $125,2 \pm 28,4$ & 0,086 \\
VO2 pico (mL/kg/min) & $19,7 \pm 5,9$ & $18,1 \pm 5,4$ & 0,491 \\
VO2 pico $(\%)$ & $60,8 \pm 17,2$ & $62,6 \pm 20,3$ & 0,814 \\
V $/$ VO2 & $34,5(31-38)$ & $40(36,5-45)$ & $\mathbf{0 , 0 3 0}$
\end{tabular}

Dados com distribuição normal foram apresentados com média \pm desvio padrão. Dados com distribuição anormal foram apresentados como mediana e intervalo interquartil. LA-VO2: consumo de oxigênio no limiar anaeróbico; FC: frequência cardíaca; VO2: consumo de oxigênio; RER: razão de troca respiratória; $V_{E} / V O 2$ : equivalente respiratório de oxigênio. 


\subsection{Avaliação de preditores da melhora da capacidade de exercício após a pericardiectomia}

A melhora da capacidade de exercício foi avaliada pela variação do VO2 pico predito para a idade. Na Tabela 12 temos as associações da análise univariada com $p<0,10$.

Tabela 12 - Análise univariada dos preditores de variação do VO2 pico predito

\begin{tabular}{lcc}
\hline Parâmetro & $\mathbf{r}$ & $\boldsymbol{p}$ \\
\hline Aorta (mm) & $-0,719$ & 0,001 \\
Idade (anos) & $-0,658$ & 0,003 \\
Pressão arterial sistólica (mmHg) & $-0,417$ & 0,085 \\
Pittsburg total & 0,669 & 0,005 \\
Apneia Central (eventos/h) & $-0,433$ & 0,073 \\
Apneia mista (eventos/h) & $-0,465$ & 0,052 \\
Tempo SpO2 menor que 90\% durante o sono (min) & $-0,476$ & 0,046 \\
Duração do teste cardiopulmonar (min) & $-0,518$ & 0,033 \\
Tempo de exercício (min) & $-0,518$ & 0,033 \\
Inclinação Máxima (graus) & $-0,457$ & 0,065 \\
Limiar anaeróbico mL/kg/min & $-0,597$ & 0,015 \\
FC pico esforço (\% predito) & $-0,679$ & 0,003 \\
RER & 0,432 & 0,083 \\
\hline SpO2: saturaça perifeica de oxigênio; RER: &
\end{tabular}

SpO2: saturação periférica de oxigênio; RER: razão de troca respiratória.

$\mathrm{Na}$ análise multivariada, idade foi o único preditor independente de melhora da capacidade de exercício. O modelo final é definido pela fórmula: $\Delta$ VO2 pico $(\%)=89,5-1,17 x$ idade (Figura 8) 


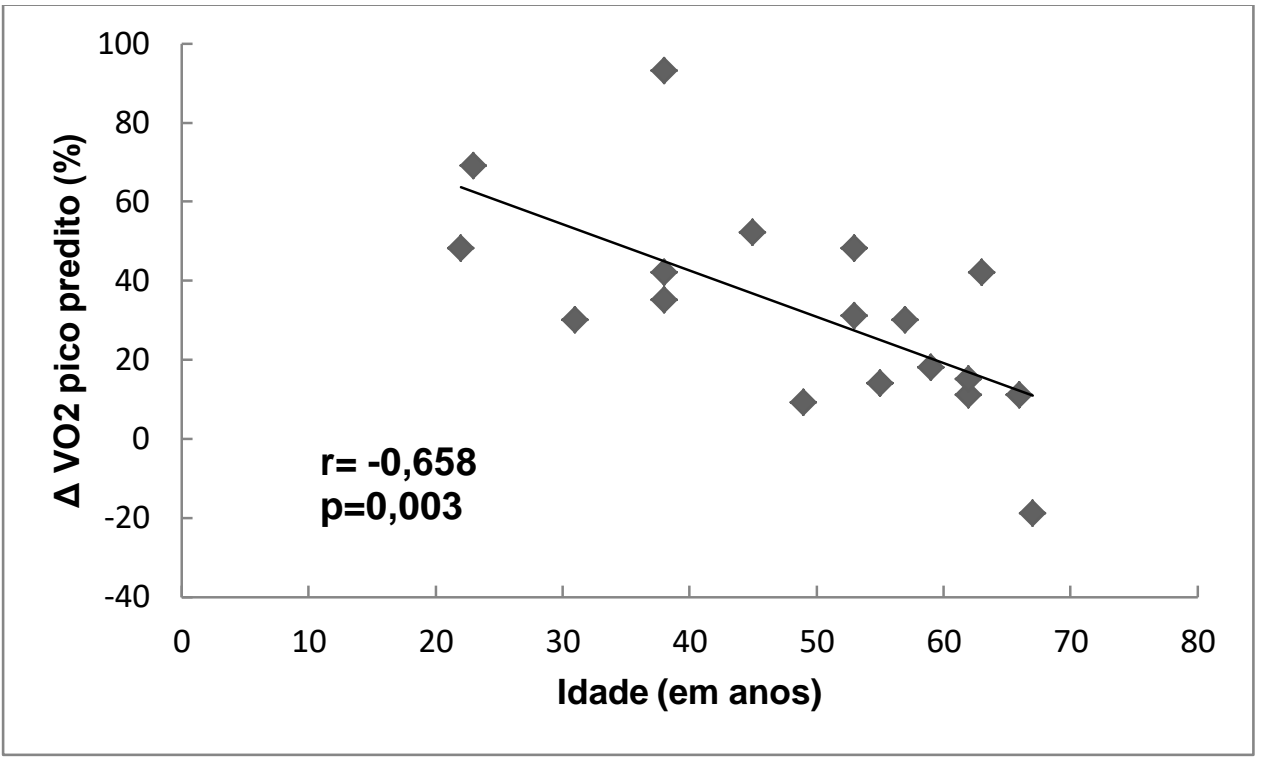

Figura 8 - Correlação entre a variação do VO2 pico predito e idade. 
Discussão 


\section{DISCUSSÃO}

Nós observamos em uma coorte de pacientes com pericardite constritiva crônica sintomática melhora dos sintomas, da capacidade funcional, da qualidade de vida e do sono após a pericardiectomia. Além disso, identificamos alta prevalência de apneia do sono nessa população, sem mudança significativa após o procedimento.

\subsection{Características da amostra}

Na seleção de pacientes, tivemos o cuidado de definir como critérios de exclusão a obesidade e miocardiopatias de outras etiologias. Nosso objetivo foi aumentar a validade interna do trabalho, reduzindo fatores de confusão para análise da capacidade de exercício e apneia do sono.

Quando comparada às principais séries de casos da literatura, nossa casuística apresentou algumas particularidades. São indivíduos jovens, com idade média de 45 anos e com poucas morbidades. Outro dado que chama a atenção é a etiologia idiopática em $76 \%$ dos casos. No importante estudo de Bertog et al, em série de 163 pacientes da Cleveland Clinic, a idade média foi maior que 50 anos e com predomínio de etiologia idiopática (46\%) e póscirúrgica (37\%). ${ }^{5}$ No estudo de Ling, em série da Mayo Clinic com 135 pacientes, os casos idiopáticos somaram $33 \% .{ }^{10}$ Considerando as características no nosso sistema público de saúde (dificuldade de acesso, recursos limitados), é possível que essas diferenças tenham ocorrido por um viés de sobrevivência, já que em indivíduos jovens e com etiologia idiopática o prognostico é melhor. Além disso, observamos em nossa amostra um longo tempo decorrido entre o início dos sintomas e a pericardiectomia. Nessa situação, há maior chance para a fibrose e calcificação do pericárdio, o que prejudica o diagnóstico histológico principalmente de casos pós-infecciosos (tuberculose e infecções virais). De qualquer forma, é intrigante o baixo número de casos pós-cirúrgicos em nossa casuística, uma vez que o Instituto do Coração realiza cerca de cinco mil cirurgias cardíacas por ano. Diante disso, nós especulamos que fatores ambientais e predisposição genética estejam 
implicados na patogenia da pericardite constritiva crônica. Essa hipótese deverá ser testada em estudos futuros.

\subsection{Teste de esforço cardiopulmonar}

Diversos estudos têm avaliado o impacto da pericardiectomia na classe funcional de pacientes com PCC, no entanto, a maioria são séries de casos retrospectivas. $5,10,73$ Essa metodologia está sujeita a muitos vieses, especialmente de seleção e aferição. Nosso estudo foi o primeiro a avaliar prospectivamente 0 teste cardiopulmonar de esforço em pacientes consecutivos com pericardite constritiva crônica. Em nossa amostra, os pacientes apresentaram no período pré-operatório redução significativa da capacidade de exercício com apenas $61 \%$ do VO2 pico predito para idade e sexo. Após a pericardiectomia, observamos elevação do VO2 pico para $83 \%$ do predito, além de melhora da eficiência ventilatória, limiar anaeróbico, velocidade da esteira rolante e frequência cardíaca máxima. Outro dado relevante é que os pacientes mais velhos parecem apresentar menor benefício com a cirurgia. $\mathrm{O}$ exame se mostrou seguro e com boa reprodutibilidade. Além disso, os nossos resultados do teste basal são semelhantes aos de estudos com IC de outras etiologias. ${ }^{74,75}$

O teste cardiopulmonar é a ferramenta mais útil para avaliar de maneira objetiva a capacidade de exercício de pacientes com insuficiência cardíaca sistólica e diastólica. O exame permite a avaliação do prognóstico, da eficácia do tratamento e auxilia na indicação de transplante cardíaco. ${ }^{76-78}$ Além disso, tem papel fundamental na prescrição de exercícios e programas de reabilitação.68 Em pacientes com fração de ejeção preservada, estudos recentes têm demonstrado o valor do consumo máximo de oxigênio (VO2 pico) e da eficiência ventilatória ( $\mathrm{V}_{\mathrm{E}} / \mathrm{VCO}$ ) como preditores de mortalidade e hospitalização por causas cardíacas. ${ }^{79,80}$ Além disso, parâmetros do teste cardiopulmonar parecem apresentar correlação com o grau de disfunção diastólica. ${ }^{80}$ Em um estudo com 156 pacientes com IC diastólica secundária a miocardiopatia hipertrófica, o VO2 pico e $\mathrm{V}_{\mathrm{E}} / \mathrm{VCO} 2$ slope se associaram de maneira independente com desfechos clínicos. Ademais, o $\mathrm{V}_{\mathrm{E}} / \mathrm{VCO} 2$ slope 
apresentou correlação com a função diastólica e volume atrial esquerdo. ${ }^{81} \mathrm{Em}$ estudo de Yan et al, o BNP sérico e $V_{E} / V C O 2$ foram fortes preditores de mortalidade em uma coorte de 224 pacientes com IC diastólica e média do VO2 pico de $17 \mathrm{~mL} / \mathrm{kg} / \mathrm{min} .{ }^{79} \mathrm{Em}$ nossa casuística, a média do VO2 pico foi $18 \mathrm{~mL} / \mathrm{kg} / \mathrm{min}$ em indivíduos com média de idade 23 anos menor. Assim, é plausível supor um papel importante de variáveis do teste cardiopulmonar na definição de prognóstico de pacientes com pericardite constritiva. Essa hipótese deverá ser testada em estudos com maior tempo de seguimento.

O achado da idade como preditor independente de melhora da capacidade funcional é relevante, pois indica que em pacientes mais velhos 0 benefício da cirurgia parece ser menor. Entretanto, esse achado deve ser interpretado com cautela, uma vez que a influência de fatores periféricos (ex. massa muscular) que afetam a capacidade de exercício não foi testada em nosso modelo. ${ }^{82}$

Atualmente, a indicação de pericardiectomia em pacientes com PCC é feita com base em dados essencialmente clínicos. Em nossa experiência, essa avaliação é imprecisa em alguns casos. O uso de diuréticos pode mascarar sinais de hipervolemia e dispneia em repouso. Ademais, por vezes dificulta a documentação da fisiologia constritiva em exames não invasivos. Nesse contexto, o teste cardiopulmonar pode ser útil para definir de maneira objetiva a capacidade de exercício e função cardiorrespiratória, auxiliando na tomada de decisão.

\subsection{Estudo do sono}

Em nossa casuística a apneia foi frequente e acompanhada de má qualidade do sono. Houve predomínio de hipopneias e correlação do índice de apneia-hipopneia com EuroSCORE e níveis séricos de BNP. Além disso, a pericardiectomia apresentou efeito neutro no índice de apneia-hipopneia, porém com melhora da qualidade do sono. Outro dado relevante é que os pacientes com apneia do sono apresentaram limiar anaeróbico inferior ao de pacientes sem apneia. 
Estudos prévios têm descrito a associação entre apneia do sono e IC com fração de ejeção preservada, no entanto não há estudos específicos com pacientes com PCC. ${ }^{83-85}$ Além disso, é importante ressaltar que a maioria incluiu pacientes idosos, com sobrepeso e múltiplas morbidades, o que pode representar um viés de seleção. Por outro lado, a nossa amostra foi composta por pacientes relativamente jovens, não obesos, e com hipertensão e diabetes em menos de $20 \%$ dos casos. Assim, é plausível a nossa hipótese de que a apneia do sono seja resultado das alterações hemodinâmicas e neurohormonais da pericardite constritiva.

Em estudo de 244 pacientes com média de idade de 66 anos e IC com fração de ejeção preservada, Bitter et al demonstraram apneia do sono (IAH $\geq$ 5 eventos/hora) em $69 \%$ dos casos. Além disso, os pacientes com apneia apresentaram maiores níveis de NT-pro-BNP, menor capacidade de exercício e pior função diastólica quando comparados aos pacientes sem apneia do sono. ${ }^{83}$ Posteriormente, Pedrosa et al demonstraram que a apneia do sono é frequente e está independentemente associada à fibrilação atrial em pacientes com miocardiopatia hipertrófica e fração de ejeção preservada. ${ }^{86}$ Nossos resultados corroboram e complementam esses achados.

Considerando o impacto na função cardiorrespiratória observado após a pericardiectomia, é intrigante o efeito neutro sobre a apneia do sono. Em estudo de Gabor, a terapia de ressincronização reduziu a apneia de pacientes com IC sistólica. ${ }^{87}$ Em pacientes com cardiopatia valvar, Abe demonstrou que o tratamento cirúrgico foi capaz de reduzir a apneia central do sono, mas não a obstrutiva. ${ }^{88}$ Posteriormente, Bucca et al demonstraram que o tratamento da hipervolemia com diuréticos reduziu a apneia do sono obstrutiva (IAH de 75 para 57 eventos/hora, $\mathrm{P}<0,001)$ em pacientes com IC diastólica. ${ }^{89}$ Algumas hipóteses podem explicar os nossos resultados. Primeiro, apesar da melhora da capacidade cardiopulmonar, não houve completa normalização da hemodinâmica cardíaca. De fato, em $40 \%$ da amostra permaneceu a turgência jugular no pós-operatório e em $24 \%$ o edema de membros inferiores. Além disso, não houve mudança significativa da circunferência cervical. Segundo, 
apesar de não haver diferença estatisticamente significante, os pacientes com apneia do sono tenderam a ser mais velhos. Em conjunto, esses achados demonstram a persistência de mecanismos fisiopatogênicos associados à apneia do sono. Por fim, o tempo de seis meses para reavaliação dos pacientes após a pericardiectomia foi extrapolado com base em estudos prévios com outras causas de IC. ${ }^{87,90}$ Entretanto, esse tempo pode não ter sido suficiente para se alcançar efeito pleno da pericardiectomia sobre a hemodinâmica cardíaca. No tocante à melhora da qualidade do sono, é provável que seja o resultado da melhora de sintomas físicos e psicológicos relacionados à $\mathrm{PCC}$.

\subsection{Ecocardiograma}

Em nossa casuística, o ecocardiograma revelou como principais achados: fração de ejeção preservada, e' septal aumentado e annulus reversus, variação respiratória do septo interventricular, dilatação e ausência de colapso inspiratório de veia cava inferior. Após a pericardiectomia, houve significativa redução do e' septal, bem como da variação respiratória da veia cava inferior.

Em estudo de Welch et al três variáveis foram associadas de maneira independente com o diagnóstico de pericardite constritiva: variação respiratória do septo interventricular, e' mitral maior que $9 \mathrm{~cm} / \mathrm{s}$ e aumento do fluxo diastólico reverso em veias hepáticas. A presença de variação respiratória septal associada a um segundo critério apresentou sensibilidade de $87 \%$ e especificidade de $91 \%$ para o diagnóstico de PCC. ${ }^{67}$ Esses dados são concordantes com nossos resultados. Em nossa amostra a variação respiratória septal e annulus reversus foram presentes em 73,9\% dos casos. Além disso, todos os casos apresentaram média do e' septal maior que $9 \mathrm{~cm} / \mathrm{s}$. A despeito desses achados, em nossa experiência o ecocardiograma tem se mostrado limitado para o diagnóstico de pericardite constritiva no ambiente fora da pesquisa. Em estudo da vida real publicado pelo nosso grupo em 2013, apenas $63 \%$ dos pacientes com PCC confirmada por cirurgia tinham ecocardiograma inicial sugestivo da doença. ${ }^{91}$ Essa pode ser uma das 
explicações para o diagnóstico tardio e longo tempo de sintomas em nossos pacientes.

Em estudos prévios a média do e' septal de pacientes com PCC variou de 9-12 cms/s. ${ }^{16,92,93}$ No interessante trabalho de Veress et al, o e' septal de pacientes com PCC idiopática foi maior quando comparado aos casos de PCC secundária. Isto porque a presença de lesão miocárdica concomitante comum nos casos secundários a radioterapia e pós-cirurgia cardíaca - pode reduzir a velocidade do Doppler tecidual. ${ }^{93} \mathrm{Em}$ nossa amostra a média do e' foi $15 \mathrm{~cm} / \mathrm{s}$. Esse achado reflete o predomínio de casos idiopáticos. Além disso, demonstra uma exagerada deformação longitudinal do septo em relação à parede livre do VE, provavelmente sugerindo constrição mais grave.

Apesar da melhora dos sintomas, não houve normalização da hemodinâmica cardíaca após a pericardiectomia, conforme pode ser observado pelos parâmetros de Doppler e avaliação da veia cava. De fato, estudos prévios revelam resultados semelhantes. Em 1999 Senni et al demonstraram enchimento ventricular anormal em $59,5 \%$ dos casos num período médio de três meses após a pericardiectomia. ${ }^{94}$ Posteriormente, Motoki et al demonstraram em uma série de 52 pacientes a redução do e' e aumento dos volumes sistólico e diastólico do ventrículo esquerdo; os átrios apresentaram melhora da função, entretanto, não sofreram remodelamento. ${ }^{95}$ Existem algumas hipóteses para esses achados. Primeiro, em pacientes com longo tempo de sintomas e presença de calcificação a ressecção do pericárdio pode não ser completa. ${ }^{96,97}$ Segundo, a extensão do processo inflamatório pericárdico ao miocárdio pode resultar em lesão de fibras miocárdicas e fibrose, com consequente miocardiopatia. ${ }^{98}$ Terceiro, a compressão extrínseca do pericárdio sobre o miocárdio leva à redução da pressão transmural com remodelamento e atrofia das fibras miocárdicas. Assim, após a pericardiectomia, pode ocorrer a síndrome de descompressão, em que o miocárdio atrofiado e desadaptado é incapaz de manter o débito cardíaco. ${ }^{99}$ Quarto, mesmo na ausência de doença coronária obstrutiva, pode ocorrer isquemia em decorrência de lesão coronária por cicatrizes/aderências e piora 
do fluxo coronário em virtude do aumento da pressão diastólica ${ }^{94} \mathrm{Em}$ conjunto, esses fatores podem contribuir para a disfunção miocárdica pós-operatória e em alguns casos persistência da insuficiência cardíaca.

\subsection{BNP}

O peptídeo natriurético tipo B é produzido nos cardiomiócitos ventriculares em resposta à distensão e é amplamente utilizado como ferramenta diagnóstica e prognóstica na insuficiência cardíaca. ${ }^{100-101}$ Os pacientes com PCC geralmente apresentam níveis mais baixos de BNP em comparação com outras causas de insuficiência cardíaca, em virtude do menor estresse transmural proporcionado pelo pericárdio inelástico circunjacente. ${ }^{19,102}$ No estudo de Leya et al, pacientes com PCC apresentaram níveis séricos de BNP significativamente menores quando comparados a pacientes com miocardiopatia restritiva com pressões de enchimento ventricular semelhantes (128 pg/mL versus $852 \mathrm{pg} / \mathrm{mL}, \mathrm{p}<0,001$, respectivamente). Posteriormente, Babuin demonstrou haver diferença nos níveis de BNP entre pacientes com PCC idiopática e PCC secundária a cirurgia/radioterapia: BNP idiopáticos 80 (44-193) pg/mL versus BNP secundários 278 (118-526), $p<0,05$. Esses dados sugerem que o BNP parece estar mais elevado nos casos de PCC em cuja mortalidade é maior. Em nossa amostra os níveis de BNP foram semelhantes aos citados. Entretanto, não encontramos correlação com o grau de função diastólica ou capacidade de exercício. Após a pericardiectomia, houve significativa redução dos níveis de BNP, provavelmente refletindo melhora da função diastólica e redução das pressões de enchimento ventricular.

\subsection{Limitações}

Nosso estudo apresenta algumas limitações. A amostra foi composta por pacientes jovens com predomínio de etiologia idiopática em centro terciário de cardiologia, o que pode representar viés de seleção e limitar a validade externa dos resultados. Além disso, o tamanho amostral de 25 pacientes limita o poder do estudo, e em parte pode justificar o resultado neutro da pericardiectomia na 
apneia do sono. Cabe ressaltar, no entanto, que se trata de doença rara e pouco diagnosticada, e que são escassos os estudos prospectivos na literatura. O ecocardiograma foi realizado com dificuldade técnica em porcentagem significativa da amostra, o que dificultou a análise e interpretação de algumas variáveis. Além disso, por dificuldades logísticas, o exame foi avaliado uma vez por um mesmo examinador, não sendo possível avaliar a reprodutibilidade de resultados, ou seja, a variabilidade intra e inter-observador. No entanto, foi realizado por examinador experiente e que estava cego para os resultados das demais avaliações.

Por último, por se tratar de estudo observacional, não realizamos controle das intervenções (medicações, reabilitação) utilizadas no pré e pósoperatório, o que pode representar um fator de confusão.

\subsection{Perspectivas}

A pericardite constritiva é uma doença com patogenia complexa e ainda pouco compreendida. Assim, estudos que explorem os mecanismos que levam pacientes com pericardite aguda a desenvolverem pericardite constritiva são fundamentais para definição de novos alvos terapêuticos. No interessante estudo de Liu et al, o aumento da expressão de TGF- $\beta 1$ (Transforming growth factor beta 1) nas células intersticiais do pericárdio de pacientes com PCC idiopática parecem se correlacionar com a presença de fibrose e calcificação. ${ }^{103}$ Não está claro, entretanto, se essa via pode ser um alvo terapêutico.

A pericardiectomia para pacientes com PCC é um procedimento com mortalidade até quatro vezes maior que a da cirurgia de revascularização miocárdica. Entretanto, não dispomos de ferramentas de avaliação de risco precisas. Nesse contexto, um estudo multicêntrico, do tipo coorte retrospectivo, com grande número de pacientes torna-se desejável. Poderia tanto identificar novos e mais precisos preditores de risco como testar a validade dos escores tradicionais (EuroSCORE).

Finalmente, com base em nossos resultados, acreditamos ser o teste cardiopulmonar uma ferramenta segura e promissora para avaliação de 
pacientes com PCC. Dessa forma, seu uso em estudos maiores, com longo tempo de seguimento e diferentes etiologias deve ser encorajado. 
Conclusões 


\section{CONCLUSÕES}

$\checkmark$ Pacientes com PCC sintomática apresentaram, seis meses após a cirurgia de pericardiectomia, melhora da capacidade funcional e da qualidade de vida.

$\checkmark$ A apneia do sono se mostrou frequente e com predomínio de hipopneias. Além disso, apresentou correlação com níveis séricos de BNP e EuroSCORE no pré-operatório.

$\checkmark$ índice de apneia-hipopneia não apresentou mudanças significativas após a pericardiectomia. A despeito disso, houve melhora da qualidade do sono.

$\checkmark$ O ecocardiograma revelou redução da fisiologia constritiva após a pericardiectomia. Entretanto, não houve normalização da hemodinâmica cardíaca em seis meses.

$\checkmark$ Os níveis de BNP foram pouco elevados e apresentaram redução após a pericardiectomia. 
Anexos 


\section{ANEXOS}

\section{ANEXO A}

\section{HOSPITAL DAS CLÍNICAS DA FACULDADE DE MEDICINA DA UNIVERSIDADE DE SÃO PAULO-HCFMUSP}

TERMO DE CONSENTIMENTO LIVRE E ESCLARECIDO

DADOS DE IDENTIFICAÇÃO DO SUJEITO DA PESQUISA OU RESPONSÁVEL LEGAL

1. NOME:

DOCUMENTO DE IDENTIDADE № :

SEXO : .M $\square \mathrm{F}$

DATA NASCIMENTO:

№

APTO:

BAIRRO:

CIDADE

CEP:

TELEFONE:

DDD

$(\ldots \ldots \ldots \ldots)$

2.RESPONSÁVEL

LEGAL

NATUREZA

(grau

de

parentesco,

tutor,

curador

etc.)

DOCUMENTO DE IDENTIDADE : SEXO: $M \square \quad F \square$

DATA NASCIMENTO:

ENDEREÇO:

№

APTO:

BAIRRO:

CIDADE:

CEP:

TELEFONE:

DDD

$(\ldots \ldots \ldots \ldots . .$.

\section{DADOS SOBRE A PESQUISA}

1. TÍTULO DO PROTOCOLO DE PESQUISA: Avaliação da apnéia do sono e aspectos morfofuncionais em pacientes com pericardite constritiva submetidos a pericardiectomia.

PESQUISADOR : Dr. Fábio Fernandes

CARGO/FUNÇÃO: Professor Livre-docente, Medico Assistente INSCRIÇÃO CONSELHO REGIONAL № 75.597

UNIDADE DO HCFMUSP: Instituto do Coração - Unidade Clínica de Miocardiopatias 
3. AVALIAÇÃO DO RISCO DA PESQUISA:

RISCO MÍNIMO

Risco baixo X
RISCO MÉDIO

RISCO MAIOR

4.DURAÇÃO DA PESQUISA : 6 meses

1 - Desenho do estudo e objetivo(s): essas informações estão sendo fornecidas para sua participação voluntária neste estudo, que visa avaliar a presença de doença do sono e aspectos funcionais em pacientes com pericardite constritiva que apresentam indicação de cirurgia do pericárdio e são acompanhados no Ambulatorio da Unidade Clínica de Miocardiopatias - Incor/ HC-FMUSP. Esta pesquisa não irá interferir no seu tratamento. O procedimento cirúrgico e os cuidados pré e pós operatórios serão prestados ao $\operatorname{Sr}(a)$ da mesma forma, participando da pesquisa ou não. A única diferença é que esta pesquisa propõe que o $\operatorname{Sr}(a)$ faça alguns exames específicos ,além dos que já são realizados de rotina, antes e seis meses após a cirurgia.

2 - Conforme já estava previsto no seu acompanhamento ambulatorial, o $\operatorname{Sr}(a)$ será convocado para internação para realização da cirurgia de ressecção do pericárdio. Antes do procedimento, caso $\circ \mathrm{Sr}(\mathrm{a})$ autorize, serão realizados os seguintes procedimentos:

Ergoespirometria: $\mathrm{O}$ sr(a) respirará através de um bucal conectado a um aparelho (não respirará pelo nariz) e realizará uma sessão de exercício na esteira rolante cuja carga iniciará baixa e irá aumentando até o máximo que o sr(a) aguentar, por aproximadamente 10 minutos. Essa avaliação serve para medir a sua capacidade física e ver como seu organismo (principalmente o seu coração e pulmão) responde ao esforço.

Microneurografia: serão colocadas duas agulhas muito finas na sua perna, localizadas um pouco abaixo do seu joelho e com distância aproximada de $1 \mathrm{~cm}$ entre elas, para sabermos a quantidade de atividade do seu nervo da perna.

Polissonografia: este exame é realizado no período noturno e tem como objetivo avaliar a qualidade do seu sono. Antes do inicio será aplicado um questionário com perguntas simples sobre a sua rotina e a maneira como o $\mathrm{Sr}(\mathrm{a})$ dorme. O exame é realizado com a colocação de alguns fios e pequenos adesivos na sua pele, na região da cabeça, no rosto, no tórax e abdome. Durante o seu sono, estes aparelhos irão monitorar a sua respiração e movimentos do seu corpo.

3 - Relação dos procedimentos rotineiros e como são realizados - coleta de sangue por punção periférica da veia do antebraço; raio-x do tórax; ecocardiograma, que consiste em ultrassonografia para avaliação do coração, além dos exames descritos no item anterior; Seis meses após a cirurgia o Sr(a) será convocado para repetir todos os exames. 
4 - Descrição dos desconfortos e riscos esperados nos procedimentos dos itens 2 e 3;

Polissonografia: este exame praticamente não apresenta riscos, já que é um exame amplamente utilizado e testado. O maior desconforto será dormir com alguns aparelhos conectados ao corpo. Você não sentirá dor ou terá qualquer prejuízo a sua saúde em decorrência do procedimento.

Ergoespirometria: $O$ fato do sr(a) respirar só pela boca nesse exame pode deixar a sua boca um pouco seca. Por ser um teste máximo, o $\operatorname{sr}(a)$ estará sujeito aos riscos que ocorrem quando o sr(a) faz um esforço (sua pressão pode aumentar exageradamente, podem ocorrer arritmias ou isquemia do coração), porém, quando o médico cardiologista que estará realizando seu exame observar qualquer alteração que envolva um risco maior para o sr(a), o teste será interrompido.

Microneurografia: Durante a colocação das agulhinhas na sua perna, você poderá ter sensação de leve dor no local onde a agulha será introduzida ou "choquinhos" no peito do pé e dedos do pé. Após o exame, você poderá sentir leve dor ou um leve choque ao tocar no local onde foi colocada a agulha ou até um pouco de fraqueza muscular na perna durante as duas primeiras semanas após o exame. Raramente (1 a cada 600 casos), estas sensações podem durar por um período de até 2-3 meses.

5 - Benefícios para o participante: Não há benefício direto para o participante. Trata-se de estudo que pretende avaliar a relação entre apnéia do sono e capacidade funcional em pacientes com pericardite constritiva. Somente no final do estudo poderemos concluir a presença de algum benefício.

6 - Relação de procedimentos alternativos que possam ser vantajosos, pelos quais o paciente pode optar: nenhum.

7 - Garantia de acesso: em qualquer etapa do estudo, você terá acesso aos profissionais responsáveis pela pesquisa para esclarecimento de eventuais dúvidas. $O$ principal investigador é o Dr Fábio Fernandes, que pode ser encontrado no endereço Unidade Clínica de Miocardiopatias - Andar B, Instituto do Coração, Av. Dr. Enéas de Carvalho Aguiar, 44, CEP: 05403-900, Telefone(s) (11) 2661-5057. Se você tiver alguma consideração ou dúvida sobre a ética da pesquisa, entre em contato com o Comitê de Ética em Pesquisa (CEP) - Rua Ovídio Pires de Campos, 225 - 5aaar tel: 2661-6442 ramais 16, 17, 18 ou 20 - e-mail: cappesq@hcnet.usp.br.

8 - É garantida a liberdade da retirada de consentimento a qualquer momento e deixar de participar do estudo, sem qualquer prejuízo à continuidade de seu tratamento na Instituição;

09 - Direito de confidencialidade - As informações obtidas serão analisadas em conjunto com outros pacientes, não sendo divulgado a identificação de nenhum paciente;

10 - Direito de ser mantido atualizado sobre os resultados parciais das pesquisas, quando em estudos abertos, ou de resultados que sejam do conhecimento dos pesquisadores; 
11 - Despesas e compensações: não há despesas pessoais para o participante em qualquer fase do estudo, incluindo exames e consultas. Também não há compensação financeira relacionada à sua participação. Se existir qualquer despesa adicional, ela será absorvida pelo orçamento da pesquisa.

12 - Serão armazenados e congelados tubos de sangue dos pacientes participantes para realização de estudos futuros. Será resguardado absoluto sigilo em relação à identidade dos pacientes;

Acredito ter sido suficientemente informado a respeito das informações que li ou que foram lidas para mim, descrevendo o estudo: Avaliação da apnéia do sono e aspectos morfofuncionais em pacientes com pericardite constritiva submetidos a pericardiectomia.

Eu discuti com o Dr. Fábio Fernandes sobre a minha decisão em participar nesse estudo. Ficaram claros para mim quais são os propósitos do estudo, os procedimentos a serem realizados, seus desconfortos e riscos, as garantias de confidencialidade e de esclarecimentos permanentes. Ficou claro também que minha participação é isenta de despesas e que tenho garantia do acesso a tratamento hospitalar quando necessário. Concordo voluntariamente em participar deste estudo e poderei retirar o meu consentimento a qualquer momento, antes ou durante o mesmo, sem penalidades ou prejuízo ou perda de qualquer benefício que eu possa ter adquirido, ou no meu atendimento neste Serviço.

Assinatura do paciente/representante legal

$D$

Assinatura da testemunha

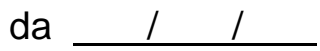

para casos de pacientes menores de 18 anos, analfabetos, semi-analfabetos ou portadores de deficiência auditiva ou visual.

(Somente para o responsável do projeto)

Declaro que obtive de forma apropriada e voluntária o Consentimento Livre e Esclarecido deste paciente ou representante legal para a participação neste estudo. 
AsAssinatura do responsável pelo estudo D $1 / 1$ 


\section{ANEXO B}

\section{Protocolo de Pesquisa - Pericardite Constritiva}

\section{Identificação}

Nome:

Idade. RGHC

Naturalidade: Procedência

Profissão: Estado Civil:

Telefone Celular: Telefone Residencial:.

\section{Diagnósticos}

1

2

3

4

5

Início do sintomas $(\ldots . . . / . . . / . . .$.

Data Diagnóstico (...../..........)

Data cirurgia $(\ldots . . . / \ldots . . . . . .$.

\section{Antecedentes:}

\begin{tabular}{|c|c|}
\hline ( ) NYHA ................ & ( )Radioterapia \\
\hline ( )Hipertensão & ( )Tuberculose \\
\hline ( )Diabetes & ( )Pericardite aguda \\
\hline ( )Dislipidemia & ( )Neoplasia \\
\hline ( )Hipotiroidismo & ( )Doenças do colágeno \\
\hline ( )Tabagismo & ( )Vasculite \\
\hline ( )DPOC & ( )Trauma torácico \\
\hline ( )Doença Arterial Coronária & ( )Cirurgia Cardíaca \\
\hline ( IAM prévio & ( )Sarcoidose/ Amioloidose \\
\hline
\end{tabular}

\section{Medicações uso domiciliar:}

1

2 


\section{Exame físico}

Peso:

..Altura:

IMC:

.CA:_.....PA:_......FC:

( )Estase jugular ( )Edema de MMII ( )Sinal de Kussmaul ( )Pulso Paradoxal

$\begin{array}{llll}\text { ( ) Knock pericárdico ( )B3 } & (\text { ) B4 Atrito pericárdico }\end{array}$

( ) Ascite

Observações:

\section{Exames pré op}

( ) ECG $(\ldots . . . / \ldots . . . . . . .):$.

( ) Radiografia de tórax(...../............):.

( ) Ecocardiograma(...../...........):

( ) $\operatorname{RNM}(\ldots . . . / \ldots . . . . . .):$.

( ) Espirometria(...../...../....):

( ) Polissonografia(...../...../.....):..

( ) Ergoespirometria(................):

Laboratório Pré-op(...../...../.....)

\begin{tabular}{|l|l|l|l|l|l|}
\hline HB & SODIO & & FALC & \\
\hline HT & & POTASSIO & & INR & \\
\hline LEUCO & & TGO & & TTpa & \\
\hline PLT & TGP & & BNP & \\
\hline UREIA & BILI & & VHS & \\
\hline CREAT & GGT & & PCR & \\
\hline
\end{tabular}

Swan-Ganz pré-op

\begin{tabular}{|l|l|l|l|l|l|l|l|l|}
\hline IC & PAP & PAPm & PAD & PCP & IRVP & IRVS & PA & FC \\
\hline & & & & & & & & \\
\hline
\end{tabular}

Intra-Operatório

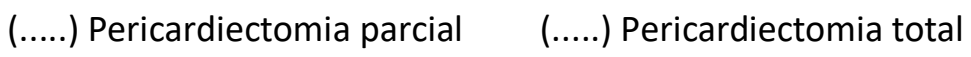

(....) CABG associada (....) Cirugia valvar associada (....) CEC

Intercorrências: 
Biópsia pericárdica $(. . . . . / . . . . / . . . .)$.

\section{Exames pós-operatórios}

Exame físico

Peso:..............Altura:.................IMC:..............CA:...... PA:.......FC:........

( ) Estase jugular ( )Edema de MMII ( )Sinal de Kussmaul ( )Pulso Paradoxal

$\begin{array}{llll}\text { ( ) Knock pericárdico ( )B3 } & (\text { ) B4 Atrito pericárdico }\end{array}$

( ) Ascite

Observações:

( ) ECG $(\ldots . . . / \ldots . . . . . .):$.

( ) Ecocardiograma(...../..........):.

( ) Polissonografia(.........../....):.

( ) Ergoespirometria(...../...../.....):

Laboratório Pós-op(.................)

\begin{tabular}{|l|l|l|l|l|l|}
\hline HB & SODIO & & FALC & \\
\hline HT & & POTASSIO & & INR & \\
\hline LEUCO & & TGO & & TTpa & \\
\hline PLT & TGP & & BNP & \\
\hline UREIA & BILI & & VHS & \\
\hline CREAT & GGT & & PCR & \\
\hline
\end{tabular}




\section{ANEXO C}

1-Seu peso mudou nos últimos tempos?

O Aumentou $\bigcirc$ Diminuiu

O Não mudou

2-Você ronca?

O Sim O Não O Não sabe

3- Intensidade do ronco:

O Tão alto quanto a respiração

O Tão alto quanto falar

$\mathrm{O}$ Mais alto que falar

O Muito alto, ouve-se do outro quarto?

4-Freqüência do ronco:

$\mathrm{O}$ Quase todo dia

3-4 vezes por semana

O 1-2 vezes por semana

O 1-2 vezes por mês

O Nunca ou quase nunca

5-O seu ronco incomoda outras pessoas?

O Sim O Não

6-Com que freqüência suas paradas respiratórias foram percebidas?

$\mathrm{O}$ Quase todo dia

O 3-4 vezes por semana

O 1-2 vezes por semana

O 1-2 vezes por mês

O Nunca ou quase nunca

O Não aplicável - o paciente dorme só
7-Você se sente cansado ao acordar?

O Quase todo dia

3-4 vezes por semana

O 1-2 vezes por semana

O 1-2 vezes por mês

O Nunca ou quase nunca

8- Você se sente cansado durante o dia?

O Quase todo dia

O 3-4 vezes por semana

O 1-2 vezes por semana

O 1-2 vezes por mês

O Nunca ou quase nunca

9- Você alguma vez dormiu enquanto dirigia?

○ Sim O Não O Não aplicável

10 -Você tem pressão alta?

O Sim O Não O Não sabe

\begin{tabular}{|l|c|c|c|c||}
\hline \multicolumn{1}{|c|}{ SITUAÇÃO } & \multicolumn{3}{c|}{ CHANCE DE COCHILAR } \\
\hline \hline Sentado e lendo & 0 & 1 & 2 & 3 \\
\hline Assistindo TV & 0 & 1 & 2 & 3 \\
\hline Sentado em um lugar público (Ex: sala de espera, cinema, igreja, etc) & 0 & 1 & 2 & 3 \\
\hline Como passageiro de trem, carro ou ônibus, andando 1 hora sem parar & 0 & 1 & 2 & 3 \\
\hline Deitando-se para descansar à tarde, quando as circunstâncias permitem & 0 & 1 & 2 & 3 \\
\hline Sentado e conversando com alguém & 0 & 1 & 2 & 3 \\
\hline Sentado calmamente após o almoço (sem álcool) & 0 & 1 & 2 & 3 \\
\hline $\begin{array}{l}\text { Dentro de um carro, enquanto para por alguns minutos ao pegar trânsito } \\
\text { intenso }\end{array}$ & 0 & 1 & 2 & 3 \\
\hline \multicolumn{1}{|c|}{ EPWORTH } & & & \\
\hline
\end{tabular}




\section{ANEXO D}

ÍNDICE DE QUALIDADE DO SONO DE PITTSBURGH

Nome:

Código:_ Data de nascimento:

Data do preenchimento:

Instruções:

1) As questões a seguir são referentes aos hábitos de sono apenas durante o mês passado.

2) Suas respostas devem indicar o mais corretamente possível o que aconteceu na maioria dos dias e noites do mês passado.

3) Por favor, responda a todas as questões.

1) Durante o mês passado, à que horas você foi deitar à noite na maioria das vezes?

HORÁRIO DE DEITAR:

2) Durante o mês passado, quanto tempo (em minuto) você demorou para pegar no sono, na maioria das vezes?

QUANTOS MINUTOS DEMOROU PARA PEGAR NO SONO:

3) Durante o mês passado, a que horas você acordou de manhã, na maioria das vezes?

HORÁRIO DE ACORDAR: 
4) Durante o mês passado, quantas horas de sono por noite você dormiu? (pode ser diferente do número de horas que você ficou na cama)

HORAS DE SONO POR NOITE:

Para cada uma das questões seguinte escolha uma única resposta, que você ache mais correta. Por favor, responda a todas as questões.

5) Durante o mês passado, quantas vezes você teve problemas para dormir por causa de:

a) Demorar mais de 30 minutos para pegar no sono

( )nenhuma vez ( )menos de uma vez por semana

( ) luma ou duas vezes por semana ( )três vezes por semana ou mais

b) Acordar no meio da noite ou de manhã muito cedo

( )nenhuma vez ( )menos de uma vez por semana

( ) uma ou duas vezes por semana ( )três vezes por semana ou mais

c) Levantar-se para ir ao banheiro

( )nenhuma vez ( )menos de uma vez por semana

( )uma ou duas vezes por semana ( )três vezes por semana ou mais

d) Ter dificuldade para respirar

( )nenhuma vez ( )menos de uma vez por semana

( ) luma ou duas vezes por semana ( )três vezes por semana ou mais

e) Tossir ou roncar muito alto

( )nenhuma vez ( )menos de uma vez por semana

( ) uma ou duas vezes por semana ( )três vezes por semana ou mais 
f) Sentir muito frio

( )nenhuma vez ( )menos de uma vez por semana

( ) luma ou duas vezes por semana ( )três vezes por semana ou mais

g) Sentir muito calor

( ) )nenhuma vez ( )menos de uma vez por semana

( ) luma ou duas vezes por semana ( )três vezes por semana ou mais

h)Ter sonhos ruins ou pesadelos

( )nenhuma vez ( )menos de uma vez por semana

( ) uma ou duas vezes por semana ( )três vezes por semana ou mais

i) Sentir dores

( )nenhuma vez ( )menos de uma vez por semana

( ) uma ou duas vezes por semana ( )três vezes por semana ou mais

j)Outra razão, por favor, descreva:

Quantas vezes você teve problemas para dormir por esta razão durante o mês passado?

( )nenhuma vez ( )menos de uma vez por semana

( ) uma ou duas vezes por semana ( )três vezes por semana ou mais

6) Durante o mês passado, como você classificaria a qualidade do seu sono?

( )Muito boa ( )ruim 
( )Boa ( )muito ruim

7) Durante o mês passado, você tomou algum remédio para dormir, receitado pelo médico, ou indicado por outra pessoa (farmacêutico, amigo, familiar) ou mesmo por sua conta?

( )nenhuma vez ( )menos de uma vez por semana

( ) luma ou duas vezes por semana ( )três vezes por semana ou mais Qual(is)?

8) Durante o mês passado, se você teve problemas para ficar acordado enquanto estava dirigindo, fazendo suas refeições ou participando de qualquer outra atividade social, quantas vezes isso aconteceu?

( )nenhuma vez ( )menos de uma vez por semana

( ) uma ou duas vezes por semana ( )três vezes por semana ou mais

9) Durante o mês passado, você sentiu indisposição ou falta de entusiasmo para realizar suas atividades diárias?

( )Nenhuma indisposição nem falta de entusiasmo

( )indisposição e falta de entusiasmo pequenas

( ) Indisposição e falta de entusiasmo moderadas

( ) muita indisposição e falta de entusiasmo

Comentários do entrevistado (se houver):

10) Você cochila? ( ) Não （） Sim

Comentário do entrevistado (se houver):

Caso Sim -Você cochila intencionalmente, ou seja, pôr que quer?

( ) Não ( ) Sim 
Comentários do entrevistado (se houver):

Para você, cochilar é

( ) Um prazer ( )Uma necessidade ( )Outro-qual?

Comentários do entrevistado (se houver): 


\section{ANEXO E}

Minnesota Living with Heart Failure Questionnaire (Tradução para o Português)

Durante o último mês seu problema cardíaco o impediu de viver como você queria por quê?

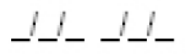

Pré $6 \mathrm{~m}$

1. Causou inchaço em seus tornozelos e pernas

() ()

2. Obrigando você a sentar ou deitar para descansar durante o dia( )

3. Tornando sua caminhada e subida de escadas dificil

() ()

4. Tornando seu trabalho doméstico dificil

() ()

5. Tornando suas saídas de casa dificil

6. Tornando dificil domir bem a noite

7. Tornando seus relacionamentos ou atividades com familiares e amigos dificil

8. Tornando seu trabalho para ganhar a vida dificil

9. Tornando seus passatempos, esportes e diversẫo dificil

10. Tornando sua atividade sexual dificil

11. Fazendo você comer menos as comidas que você gosta

12. Causando falta de ar

13. Deixando você cansado, fatigado ou com pouca energia

14. Obrigando você a ficar hospitalizado

15. Fazendo você gastar dinheiro com cuidados médicos

16. Causando a você efeitos colaterais das medicaçốes

17. Fazendo você sentir-se um peso para familiares e amigos

18. Fazendo você sentir uma falta de auto controle na sua vida

19. Fazendo você se preocupar

20. Tornando dificil você concentrar-se ou lembrar-se das coisas

21. Fazendo você sentir-se deprimido 
Referências 


\section{REFERÊNCIAS}

1. Maisch B, Seferović PM, Ristić AD, Erbel R, Rienmüller R, Adler Y, et al. Guidelines on the diagnosis and management of pericardial diseases: The Task force on the diagnosis and management of pericardial diseases of the European Society of Cardiology. Eur Heart J. 2004;25(7):587-610.

2. Kutcher MA, King SB 3rd, Alimurung BN, Craver JM, Logue RB. Constrictive pericarditis as a complication of cardiac surgery: recognition of an entity. Am J Cardiol. 1982;50:742-748.

3. Imazio M, Brucato A, Maestroni S, Cumetti D, Belli R, Trinchero R, et al. Risk of constrictive pericarditis after acute pericarditis. Circulation. 2011;124(11):1270-5.

4. Adler $\mathrm{Y}$, Charron $\mathrm{P}$, Imazio M, Badano L, Barón-Esquivias G, Bogaert J, et al. 2015 ESC Guidelines for the diagnosis and management of pericardial diseases: The Task Force for the Diagnosis and Management of Pericardial Diseases of the European Society of Cardiology ( ESC) Endorsed by: The European Association of Cardio-Thoracic Surgery (EACTS). Eur Heart J. 2015;36(42):2921-64.

5. Bertog SC, Thambidorai SK, Parakh K, Schoenhagen P, Ozduran V, Houghtaling PL, et al. Constrictive pericarditis: etiology and cause-specific survival after pericardiectomy. J Am Coll Cardiol. 2004;43(8):1445-52.

6. Montera MW, Mesquita ET, Colafranceschi AS, Oliveira Jr AC, Rabischoffsky A, lanni BM, et al. Sociedade Brasileira de Cardiologia. I Diretriz Brasileira de Miocardites e Pericardites. Arq Bras Cardiol. 2013;100(4 supl. 1):1-36.

7. Melo DT, Mady C, Ramires FJ, Dias RR, Gualandro DM, Caramelli B, et al. The value of B-type natriuretic peptide as a predictor of mortality in patients 
with constrictive pericarditis undergoing pericardiectomy. Int $\mathrm{J}$ Cardiol. 2016;205:58-9.

8. Camargo JMT, Stolf NAG, Takeda RT, Neto LF, Amauchi W, Cury LKFN, et al. Tratamento cirúrgico da pericardite constritiva. Arq Bras Cardiol. 1977;30(3):173-177.

9. Hancock EW. Differential diagnosis of restrictive cardiomyopathy and constrictive pericarditis. Heart. 2001;86(3):343-9.

10. Ling LH, Oh JK, Schaff HV, Danielson GK, Mahoney DW, Seward JB, et al .Constrictive pericarditis in the modern era: evolving clinical spectrum and impact on outcome after pericardiectomy. Circulation. 1999;100(13):1380-6.

11. Klein AL, Abbara S, Agler DA, Appleton CP, Asher CR, Hoit B, et al. American Society of Echocardiography clinical recommendations for multimodality cardiovascular imaging of patients with pericardial disease: endorsed by the Society for Cardiovascular Magnetic Resonance and Society of Cardiovascular Computed Tomography. $J$ Am Soc Echocardiogr. 2013;26(9):965-1012.

12. Nishimura RA. Constrictive pericarditis in modern era: a diagnostic dilemma. Heart. 2001;86:619-623.

13. Shabetai R, Flower NO, Guntheoroth WG. The hemodynamics of cardiac tamponade and constrictive pericarditis. Am J Cardiol. 1970;26:480-489.

14. Talreja DR, Nishimura RA, Oh JK, Holmes DR. Constrictive pericarditis in the modern era: novel criteria for diagnosis in the cardiac catheterization laboratory. J Am Coll Cardiol. 2008;51(3):315-9.

15. Santamore WP, Bartlett R, Van Buren SJ, Dowd MK, Kutcher MA. Ventricular coupling in constrictive pericarditis. Circulation. 1986;74:597-602. 
16. Kusunose K, Dahiya A, Popović ZB, Motoki H, Alraies MC, Zurick AO, et al. Biventricular mechanics in constrictive pericarditis comparison with restrictive cardiomyopathy and impact of pericardiectomy. Cir Cardiovascular Imaging. 2013;6:399-406.

17. Sengupta PP, Krishnamoorthy VK, Abhayaratna WP, Korinek J, Belohlavek M, Sundt TM $3^{\text {rd }}$, et al. Disparate patterns of left ventricular mechanics differentiate constrictive pericarditis from restrictive cardiomyopathy. JACC Cardiovasc Imaging. 2008;1:29-38.

18. Anand IS, Ferrari R, Kalra GS, Wahi PL, Poole-Wilson PA, Harris PC. Pathogenesis of edema in constrictive pericarditis. Studies of body water and sodium, renal function, hemodynamics, and plasma hormones before and after pericardiectomy. Circulation. 1991;83(6):1880-7.

19. Leya FS, Arab D, Joyal D, Shioura KM, Lewis BE, Steen LH, et al. The efficacy of brain natriuretic peptide levels in differentiating constrictive pericarditis from restrictive cardiomyopathy. J Am Coll Cardiol. 2005;45(11):1900-2.

20. Babuin L, Alegria JR, Oh JK, Nishimura RA, Jaffe AS. Brain natriuretic peptide levels in constrictive pericarditis and restrictive cardiomypathy. J Am Coll Cardiol. 2006;47(7):1489-91.

21. Sharif D, Radzievsky N, Rosenschein U. Recurrent pericardial constriction: Vibrations of the Knock, the Calcific Shield, and the Evoked Constrictive Physiology. Circulation. 2008;118:1685-1688.

22. Talreja DR, Edwards WD, Danielson GK, Schaff HV, Tajik AJ, Tazelaar $\mathrm{HD}$, et al. Constrictive pericarditis in 26 patients with histologically normal pericardial thickness. Circulation. 2003; 108(15):1852-7.

23. Yared K, Baggish AL, Picard MH, Hoffmann U, Hung J. Multimodality imaging of pericardial diseases. JACC Cardiovasc Imaging. 2010;3:650-660. 
24. Anavekar NS, Wong BF, Foley TA, Bishu K, Kolipaka A, Koo CW, et al. Index of biventricular interdependence calculated using cardiac MRI: a proof of concept study in patients with and without constrictive pericarditis. Int $J$ Cardiovasc Imaging. 2013;29(2):363-9.

25. Thavendiranathan P, Verhaert D, Walls MC, Bender JA, Rajagopalan S, Chung YC, et al. Simultaneous right and left heart real-time, free-breathing CMR flow quantification identifies constrictive physiology. JACC CardiovasC Imaging. 2012;5(1):15-24.

26. Zurick AO, Bolen MA, Kwon DH, Tan CD, Popovic ZB, Rajeswaran J, et al. Pericardial delayed hyperenhancement with CMR imaging in patients with constrictive pericarditis undergoing surgical pericardiectomy: a case series with histopathological correlation. JACC Cardiovasc Imaging. 2011;4(11):1180-91.

27. Feng D, Glockner J, Kim K, Martinez M, Syed IS, Araoz P, et al. Cardiac magnetic resonance imaging pericardial late gadolinium enhancement and elevated inflammatory markers can predict the reversibility of constrictive pericarditis after antiinflammatory medical therapy: a pilot study. Circulation. $2011 ; 124(17): 1830-7$.

28. Kushida CA, Littner MR, Morgenthaler T, Alessi CA, Bailey D, Coleman J $\mathrm{Jr}$, et al. Practice parameters for the indications for polysomnography and related procedures: an update for 2005. Sleep. 2005;28(4):499-521.

29. Kasai T, Bradley D. Obstructive sleep apnea and heart failure: pathophysiologic and therapeutic implications. J Am Coll Cardiol. 2011;57:11927.

30. Sleep-related breathing disorders in adults: recommendations for syndrome definition and measurement techniques in clinical research. The 
Report of an American Academy of Sleep Medicine Task Force. Sleep. 1999;22(5):667-689.

31. Gottlieb DJ, Yenokyan G, Newman AB, O'Connor GT, Punjabi NM, Quan SF, et al. Prospective study of obstructive sleep apnea and incident coronary heart disease and heart failure: the sleep heart health study. Circulation. 2010;122(4):352-60.

32. Drager LF, Bortolotto LA, Figueiredo AC, Silva BC, Krieger EM, LorenziFilho G. Obstructive sleep apnea, hypertension, and their interaction on arterial stiffness and heart remodeling. Chest. 2007;131(5):1379-86.

33. Naughton MT. Respiratory sleep disorders in patients with congestive heart failure. J Thorac Dis. 2015;7(8):1298-310.

34. Yumino D, Redolfi S, Ruttanaumpawan P, Su MC, Smith S, Newton GE, et al. Nocturnal rostral fluid shift: a unifying concept for the pathogenesis of obstructive and central sleep apnea in men with heart failure. Circulation. 2010;121(14):1598-605.

35. Bradley TD, Floras JS. Sleep apnea and heart failure: Part I: obstructive sleep apnea. Circulation. 2003;107(12):1671-8.

36. Bradley TD, Floras JS. Sleep apnea and heart failure: Part II: central sleep apnea. Circulation. 2003;107(13):1822-6.

37. Yumino D, Wang H, Floras JS, Newton GE, Mak S, Ruttanaumpawan P, et al. Prevalence and physiological predictors of sleep apnea in patients with heart failure and systolic dysfunction. J Card Fail 2009;15:279-85.

38. Oldenburg O, Lamp B, Faber L, Teschler H, Horstkotte D, Töpfer V. Sleep-disordered breathing in patients with symptomatic heart failure: a contemporary study of prevalence in and characteristics of 700 patients. Eur $\mathrm{J}$ Heart Fail. 2007;9(3):251-7. 
39. Pedrosa RP, Drager LF, Genta PR, Amaro AC, Antunes MO, Matsumoto AY, et al. Obstructive sleep apnea is common and independently associated with atrial fibrillation in patients with hypertrophic cardiomyopathy. Chest. 2010;137(5):1078-84.

40. Bitter T, Westerheide N, Prinz C, Hossain MS, Vogt J, Langer C, et al. Cheyne-Stokes respiration and obstructive sleep apnoea are independent risk factors for malignant ventricular arrhythmias requiring appropriate cardioverterdefibrillator therapies in patients with congestive heart failure. Eur Heart $\mathrm{J}$. 2011;32(1):61-74.

41. Pedrosa RP, Lima SG, Drager LF, Genta PR, Amaro AC, Antunes MO, et al. Sleep quality and quality of life in patients with hypertrophic cardiomyopathy. Cardiology. 2010;117(3):200-6.

42. Khayat R, Jarjoura D, Porter K, Sow A, Wannemacher J, Dohar R, et al. Sleep disordered breathing and post-discharge mortality in patients with acute heart failure. Eur Heart J. 2015;36(23):1463-9.

43. Iber C, Ancoli-Israel S, Chesson A, Quan SF. The AASM Manual for the Scoring of Sleep and Associated Events: rules, terminology, and technical specifications, First Edition. Westchester, Illinois: American Academy of Sleep Medicine, 2007.

44. Arzt M, Young T, Finn L, Skatrud JB, Ryan CM, Newton GE, et al. Sleepiness and sleep in patients with both systolic heart failure and obstructive sleep apnea. Arch Intern Med. 2006;166(16):1716-22.

45. Costa LE, Uchôa CH, Harmon RR, Bortolotto LA, Lorenzi-Filho G, Drager LF. Potential underdiagnosis of obstructive sleep apnoea in the cardiology outpatient setting. Heart. 2015;101(16):1288-92. 
46. Bradley TD, Hall MJ, Ando S, Floras SJ. Hemodynamic effects of stimulated obstructive apneas in humans with and without heart failure. Chest. 2001; 119:1827-35.

47. Somers VK, Mark AL, Zavala DC, Abboud FM. Contrasting effects of hypoxia and hypercapnia on ventilation and sympathetic activity in humans. $J$ Appl Physiol (1985). 1989;67(5):2101-6.

48. Spaak J, Egri ZJ, Kubo T, Yu E, Ando S, Kaneko Y, et al. Muscle sympathetic nerve activity during wakefulness in heart failure patients with and without sleep apnea. Hypertension. 2005;46(6):1327-32.

49. Drager LF, Bortolotto LA, Lorenzi MC, Figueiredo AC, Krieger EM, Lorenzi-Filho G. Early signs of atherosclerosis in obstructive sleep apnea. Am J Respir Crit Care Med. 2005;172(5):613-8.

50. Serizawa N, Yumino D, Kajimoto K, Tagawa Y, Takagi A, Shoda M, et al. Impact of sleep-disordered breathing on life-threatening ventricular arrhythmia in heart failure patients with implantable cardioverter-defibrillator. Am J Cardiol. 2008;102(8):1064-8.

51. Mansfield DR, Gollogly NC, Kaye DM, Richardson M, Bergin P, Naughton MT. Controlled trial of continuous positive airway pressure in obstructive sleep apnea and heart failure. Am $J$ Respir Crit Care Med. $2004 ; 169(3): 361-6$.

52. Smith LA, Vennelle M, Gardner RS, McDonagh TA, Denvir MA, Douglas $\mathrm{NJ}$, et al. Auto-titrating continuous positive airway pressure therapy in patients with chronic heart failure and obstructive sleep apnoea: a randomized placebocontrolled trial. Eur Heart J. 2007;28(10):1221-7. 
53. Lorenzi-Filho G, Genta PR, Figueiredo AC, Inoue D. Cheyne-Stokes respiration in patients with congestive heart failure: causes and consequences. Clinics (Sao Paulo). 2005;60(4):333-44.

54. Lorenzi-Filho G, Rankin F, Bies I, Douglas Bradley T. Effects of inhaled carbon dioxide and oxygen on Cheyne-Stokes respiration in patients with heart failure. Am J Respir Crit Care Med. 1999;159:1490-1498.

55. Javaheri S, Parker TJ, Liming JD, Corbett WS, Nishiyama H, Wexler L, et al. Sleep apnea in 81 ambulatory male patients with stable heart failure. Types and their prevalences, consequences, and presentations. Circulation. 1998;97(21):2154-9.

56. Cowie MR, Woehrle H, Wegscheider K, Angermann C, d'Ortho MP, Erdmann E, et al. Adaptive Servo-Ventilation for Central Sleep Apnea in Systolic Heart Failure. N Engl J Med. 2015;373(12):1095-105.

57. Bradley TD, Logan AG, Kimoff RJ, Sériès F, Morrison D, Ferguson K, et al. Continuous positive airway pressure for central sleep apnea and heart failure. N Engl J Med. 2005;353(19):2025-33.

58. Komoda T, Frumkin A, Knosalla C, Hetzer R. Child-Pugh score predicts survival after radical pericardiectomy for constrictive pericarditis. Ann Thorac Surg. 2013;96:1679-85.

59. Choudhry MW, Homsi M, Mastouri R, Feigenbaum H, Sawada SG. Prevalence and Prognostic Value of Right Ventricular Systolic Dysfunction in Patients With Constrictive Pericarditis Who Underwent Pericardiectomy. Am J Cardiol. 2015;116(3):469-73.

60. Chowdhury UK, Subramaniam GK, Kumar AS, Airan B, Singh R, Talwar $S$, et al. Pericardiectomy for constrictive pericarditis: a clinical, echocardiographic, and hemodynamic evaluation of two surgical techniques. Ann Thorac Surg. 2006;81(2):522-9. 
61. Bashi VV, John S, Ravikumar E, Jairaj PS, Shyamsunder K, Krishnaswami S. Early and late results of pericardiectomy in 118 cases of constrictive pericarditis. Thorax. 1988;43(8):637-41.

62. Cameron J, Oesterle SN, Baldwin JC, Hancock EW. The etiologic spectrum of constrictive pericarditis. Am Heart J. 1987;113:354-60.

63. Roques F, Nashef SA, Michel P, Gauducheau E, de Vincentiis C, Baudet $E$, et al. Risk factors and outcome in European cardiac surgery: analysis of the EuroSCORE multinational database of 19030 patients. Eur J Cardiothorac Surg. 1999;15(6):816-22.

64. Shroyer AL, Coombs LP, Peterson ED, Eiken MC, DeLong ER, Chen A, et al. The Society of Thoracic Surgeons: 30-day operative mortality and morbidity risk models. Ann Thorac Surg. 2003;75:1856-65.

65. George TJ, Arnaoutakis GJ, Beaty CA, Kilic A, Baumgartner WA, Conte JV. Contemporary etiologies, risk factors, and outcomes after pericardiectomy. Ann Thorac Surg. 2012;94(2):445-51.

66. Szabó G, Schmack B, Bulut C, Soós P, Weymann A, Stadtfeld S, et al. Constrictive pericarditis: risks, aetiologies and outcomes after total pericardiectomy: 24 years of experience. Eur $J$ Cardiothorac Surg. 2013;44(6):1023-8.

67. Welch TD, Ling LH, Espinosa RE, Anavekar NS, Wiste HJ, Lahr BD, et al. Echocardiographic Diagnosis of Constrictive Pericarditis: Mayo Clinic Criteria. Cir Cardiovasc Imaging. 2014;7:526-534.

68. Balady GJ, Arena R, Sietsema K, Myers J, Coke L, Fletcher GF, et al. American Heart Association Exercise, Cardiac Rehabilitation, and Prevention Committee of the Council on Clinical Cardiology; Council on Epidemiology and 
Prevention; Council on Peripheral Vascular Disease; Interdisciplinary Council on Quality of Care and Outcomes Research. Clinician's Guide to cardiopulmonary exercise testing in adults: a scientific statement from the American Heart Association. Circulation. 2010;122(2):191-225.

69. Johns MW. A new method for measuring daytime sleepiness: the Epworth sleepiness scale. Sleep. 1991;14(6):540-5.

70. Buysse DJ, Reynolds CF, Monk TH, Berman SR, Kupfer DJ. The Pittsburgh Sleep Quality Index: a new instrument for psychiatric practice and research. Psychiatry Res. 1989;28(2):193-213.

71. Carvalho VO, Guimarães GV, Carrara D, Bacal F, Bocchi EA. Validation of the Portuguese version of the Minnesota Living with Heart Failure Questionnaire. Arq Bras Cardiol. 2009;93(1):39-44.

72. Rector TS, Cohn JN. Assessment of patient outcome with the Minnesota Living with Heart Failure questionnaire: reliability and validity during a randomized, double-blind, placebo-controlled trial of pimobendan. Am Heart J. 1992;124(4):1017-25.

73. Osterberg L, Vagelos R, Atwood JE. Case presentation and review: constrictive pericarditis. West J Med. 1998;169(4):232-9.

74. Guazzi M, Myers J, Arena R. Cardiopulmonary exercise testing in the clinical and prognostic assessment of diastolic heart failure. J Am Coll Cardiol. 2005;46(10):1883-90.

75. Edelmann F, Wachter R, Schmidt AG, Kraigher-Krainer E, Colantonio C, Kamke W, et al. Effect of spironolactone on diastolic function and exercise capacity in patients with heart failure with preserved ejection fraction: the AldoDHF randomized controlled trial. JAMA. 2013;309(8):781-91. 
76. Francis DP, Shamim W, Davies LC, Piepoli MF, Ponikowski P, Anker SD, et al. Cardiopulmonary exercise testing for prognosis in chronic heart failure: continuous and independent prognostic value from VE/VCO2 slope and peak VO2. Eur Heart J. 2000;21:154-161.

77. Gitt AK, Wasserman K, Kilkowski C, Kleemann T, Kilkowski A, Bangert $M$, et al. Exercise anaerobic threshold and ventilatory efficiency identify heart failure patients for high risk of early death. Circulation. 2002;106:3079-3084.

78. Lang CC, Karlin P, Haythe J, Lim TK, Mancini DM. Peak cardiac power output, measured noninvasively, is a powerful predictor of outcome in chronic heart failure. Circ Heart Fail. 2009;2:33-38.

79. Yan J, Gong SJ, Li L, Yu HY, Dai HW, Chen J, et al. Combination of Btype natriuretic peptide and minute ventilation/carbon dioxide production slope improves risk stratification in patients with diastolic heart failure. Int $J$ Cardiol. 2013;162(3):193-8.

80. Guazzi M, Myers J, Peberdy MA, Bensimhon D, Chase P, Arena R. Cardiopulmonary exercise testing variables reflect the degree of diastolic dysfunction in patients with heart failure-normal ejection fraction. J Cardiopulm Rehabil Prev. 2010;30(3):165-72.

81. Finocchiaro G, Haddad F, Knowles JW, Caleshu C, Pavlovic A, Homburger $\mathrm{J}$, et al. Cardiopulmonary responses and prognosis in hypertrophic cardiomyopathy: a potential role for comprehensive noninvasive hemodynamic assessment. JACC Heart Fail. 2015;3(5):408-18.

82. Duscha BD, Schulze PC, Robbins JL, Forman DE. Implications of chronic heart failure on peripheral vasculature and skeletal muscle before and after exercise training. Heart Fail Rev. 2008;13:21-37. 
83. Bitter T, Faber L, Hering D, Langer C, Horstkotte D, Oldenburg O. Sleepdisordered breathing in heart failure with normal left ventricular ejection fraction. Eur J Heart Fail. 2009;11(6):602-8.

84. Herrscher TE, Akre H, Overland B, Sandvik L, Westheim AS. High prevalence of sleep apnea in heart failure outpatients: even in patients with preserved systolic function. J Card Fail. 2011;17(5):420-5.

85. Sekizuka H, Osada N, Miyake F. Sleep disordered breathing in heart failure patients with reduced versus preserved ejection fraction. Heart Lung Circ. 2013;22(2):104-9.

86. Pedrosa RP, Drager LF, Genta PR, Amaro AC, Antunes MO, Matsumoto AY, et al. Obstructive sleep apnea is common and independently associated with atrial fibrillation in patients with hypertrophic cardiomyopathy. Chest. 2010;137(5):1078-84.

87. Gabor JY, Newman DA, Barnard-Roberts V, Korley V, Mangat I, Dorian $P$, et al. Improvement in Cheyne-Stokes respiration following cardiac resynchronisation therapy. Eur Respir J. 2005;26(1):95-100.

88. Abe H, Takahashi M, Yaegashi $\mathrm{H}$, Eda S, Kitahara $\mathrm{H}$, Tsunemoto $\mathrm{H}$, et al. Valve repair improves central sleep apnea in heart failure patients with valvular heart diseases. Circ J. 2009;73(11):2148-53.

89. Bucca $C B$, Brussino L, Battisti A, Mutani R, Rolla G, Mangiardi L, et al. Diuretics in obstructive sleep apnea with diastolic heart failure. Chest. 2007;132(2):440-6. 
90. Mansfield DR, Solin P, Roebuck T, Bergin P, Kaye DM, Naughton MT. The effect of successful heart transplant treatment of heart failure on central sleep apnea. Chest. 2003;124(5):1675-81.

91. Melo DTP, Fernandes F, Salemi VMC, Buck PC, Dias RR, Tiveron MG, et al. Diagnostic challenge in constrictive pericarditis: the role of brain natriuretic peptide and image tools. In: European Society of Cardiology Congress, 2013, Amsterdan. Eur Heart J. 2013;34:695-695.

92. Kim JS, Ha JW, Im E, Park S, Choi EY, Cho YH, et al. Effects of pericardiectomy on early diastolic mitral annular velocity in patients with constrictive pericarditis. Int J Cardiol. 2009;133(1):18-22.

93. Veress G, Ling LH, Kim KH, Dal-Bianco JP, Schaff HV, Espinosa RE, et al. Mitral and tricuspid annular velocities before and after pericardiectomy in patients with constrictive pericarditis. Circ Cardiovasc Imaging. 2011;4(4):399407.

94. Senni M, Redfield MM, Ling LH, Danielson GK, Tajik AJ, Oh JK. Left ventricular systolic and diastolic function after pericardiectomy in patients with constrictive pericarditis: Doppler echocardiographic findings and correlation with clinical status. J Am Coll Cardiol. 1999;33(5):1182-8.

95. Motoki H, Alraies MC, Dahiya A, Saraiva RM, Hanna M, Marwick TH, et al. Changes in left atrial mechanics following pericardiectomy for pericardial constriction. J Am Soc Echocardiogr. 2013;26(6):640-8.

96. Somerville W. Constrictive pericarditis: with special reference to the change in natural history brought about by surgical intervention. Circulation. 1968;38(Suppl 5):102-10. 
97. Culliford AT, Lipton M, Spencer FC. Operation for chronic constrictive pericarditis: do the surgical approach and degree of pericardial resection influence the outcome significantly? Ann Thorac Surg. 1980;29:146-52.

98. Levine HD. Myocardial fibrosis in constrictive pericarditis: electrocardiographic and pathologic observations. Circulation. 1973;48:1268-81.

99. McCaughan BC, Schaff HV, Piehler JM, Danielson GK, Orszulak TA, Puga FJ, et al. Early and late results of pericardiectomy for constrictive pericarditis. J Thorac Cardiovasc Surg. 1985;89(3):340-50.

100. Harrison A, Morrison LK, Krishnaswamy P, Kazanegra R, Clopton P, Dao, et al. B-type natriuretic peptide predicts future cardiac events in patients presenting to the emergency department with dyspnea. Ann Emerg Med. 2002;39:131-8.

101. Morrison LK1, Harrison A, Krishnaswamy P, Kazanegra R, Clopton P, Maisel A. Utility of a rapid B-natriuretic peptide (BNP) assay in differentiating $\mathrm{CHF}$ from lung disease in patients presenting with dyspnea. J Am Coll Cardiol. 2002;39:202-9.

102. Karaahmet T, Yilmaz F, Tigen K, Mutlu B, Cevik C, Basaran Y. Diagnostic utility of Plasma N-Terminal Pro-B-Type natriuretic peptide and Creactive protein Levels in differential diagnosis of pericardial constriction and restrictive cardiomyopathy. Congest Heart Fail. 2009;15:265-270.

103. Liu X, Bai C, Gong D, Yuan Y, Han L, Lu F, et al. Pleiotropic effects of transforming growth factor- $\beta 1$ on pericardial interstitial cells. Implications for fibrosis and calcification in idiopathic constrictive pericarditis. J Am Coll Cardiol. 2011;57(15):1634-5. 